\title{
Development of motor control and behaviour in Asian elephants in the Kabini elephant population, southern India
}

\author{
T. REVATHE, S. ANVITHA and T.N.C. VIDYA \\ Evolutionary and Organismal Biology Unit, Jawaharlal Nehru Centre for Advanced Scientific Research (JNCASR), \\ Bengaluru, India
}

\begin{abstract}
Although neonates of precocial mammals are capable of locomotory, sensory, nutritional, and thermoregulatory independence to some extent soon after birth, they attain their adult body mass more slowly than altricial mammals, allowing for an extended period of learning or perfecting skills to an adult-like degree. Asian elephants are precocial but are nutritionally dependent on the mother for at least two years and are long-lived and social. We wanted to examine the ontogeny of trunk motor control and various behaviours in Asian elephant calves and see whether the former develops faster than the latter since limb motor control is achieved soon after birth. We collected field data on trunk use, lateralisation, and behaviours from individually identified, free-ranging elephants in southern India and examined how they were affected by age and other factors. Unlike limb motor control, we found trunk motor skills and behaviours to develop gradually with age. Trunk lateralisation occurred very early on, was not highly dependent on trunk motor skills, and is probably not a developmental marker in Asian elephants. Adult-like behaviours that required low trunk usage emerged within 3 months, while some feeding behaviours emerged later. Calves spent less time resting and more time feeding as they grew, and their activity budgets resembled those of adults only after a year; hence, mother-offspring behavioural synchrony was low for young calves and increased with age. Behavioural development and trunk motor control in Asian elephants are both gradual processes, taking about a year to mature.
\end{abstract}

KEY WORDS: ontogeny of behaviour, ethogram, calf behaviour, precocial, trunk laterality, synchrony

\section{Introduction}

Young ones of all mammalian species go through a period of, often co-occurring, anatomical, physiological, and behavioural development. The study of the ontogeny of behaviour examines when and how rudimentary forms of various behaviours of young ones become elaborated and perfected, although since the nutritional and social requirements of immatures may be different from those of mature individuals, not all behaviours shown by young ones are necessarily primitive; specific behaviours may be lost or gained depending on changes in ecology of the animals as they grow (Scott et al., 1974, Barrett and Bateson 1978, Bateson 1981, Hinde and Bateson 1984, Bateson 1987, Holekamp and Smale 1998, Bateson 2017). Two modal developmental types are found amongst mammals: precociality and altriciality. Neonates of precocial mammals are capable of locomotion soon after birth, are either entirely nutritionally independent or may forage inde- pendently of the parents while continuing to be nursed, and show sensory and thermoregulatory independence (Derrickson 1992). Neonates of altricial mammals are born helpless, often with eyes closed and devoid of hair, lacking locomotor abilities, and hence require extensive parental investment for food provisioning and thermoregulation (Derrickson 1992, Scheiber et al., 2017). Although precocial mammals are heavier at birth, born after a relatively longer gestation period than altricial mammals, they attain their adult body mass more slowly than the latter (Derrickson 1992). Hence, such neonates may have a prolonged period of dependency on the mother (Kleiman 1972, Poirier and Smith 1974, Derrickson 1992) resulting in increased time for socialisation between the mother-offspring pair (Washburn and Hamburg 1965, Kleiman 1972, Derrickson 1988) and increased opportunity for social learning and

Abbreviations used in this paper: GLM, General linear model.

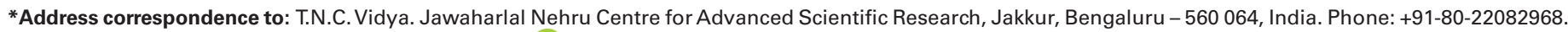
Fax: +91-80-22082766. E-mail: tncvidya@jncasr.ac.in - (iD) https://orcid.org/0000-0002-7143-9008
}

Supplementary Material (5 figures and 7 tables) for this paper is available at: https://doi.org/10.1387/ijdb.190274tv 

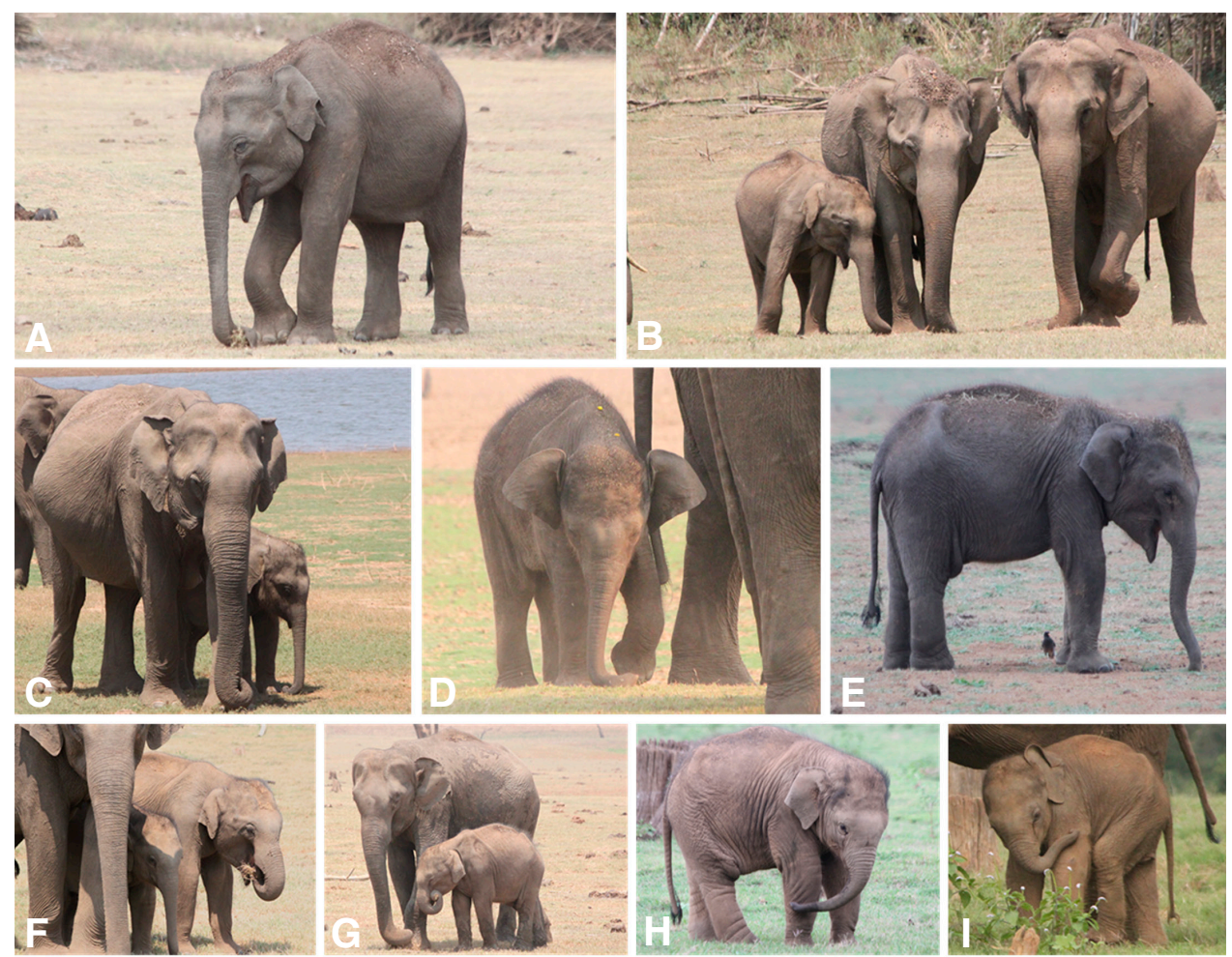

Fig. 1. Calves/juveniles showing different trunk movements. $(\mathbf{A}, \mathbf{B})$ Trunk movements used to pluck and gather vegetation successfully in (A) a clockwise direction and (B) an anticlockwise direction. (C,D) Unsuccessful attempted trunk movements to pluck/gather vegetation in (C) a clockwise direction and (D) an anticlockwise direction. (E) Calf using its trunk to touch the ground straight, without curling the tip. $(\mathbf{F}, \mathbf{G})$ Trunk used to place vegetation inside the mouth $(\mathbf{F})$ through the right side and $\mathbf{( G )}$ through the left side. $\mathbf{( H , I )}$ Trunk used to touch the body on the $\mathbf{( H )}$ right side and (I) left side. exploration while being defended by the mother and others in the group (Washburn and Hamburg 1965, Poirier and Smith 1974, Joffe 1997). Therefore, such precocial mammals, while possibly becoming adept in motor tasks fairly quickly after birth, may show more gradual and longer-term changes in behaviour (Kruuk 1972, Pratt and Anderson 1979, Nair 1989, Holekamp and Smale 1998, Mendonca et al., 2016).

The order Proboscidea (within the clade Afrotheria) has been classified as precocial by Derrickson (1992), who used four axes of developmental categories - locomotory, nutritional, sensory, and thermoregulation - to carry out such classification. Newborn elephant calves can stand up, with some assistance, within a few minutes or hours after birth (Sharma and Krishnamurthy 1984, Nair 1989, Sukumar 2003), although proper limb coordination may develop only by around one month of age (Nair 1989, Sukumar 2003). Calves also show sensory and thermoregulatory independence. However, a calf is completely dependent on its mother for nutrition during the first three months of life (Nair 1989, Sukumar 2003, Webber 2017). The only published papers on Asian elephant calf development in India were based on work carried out on semi-captive elephants held by the Forest Department (Gadgil and Nair 1984, Sharma and Krishnamurthy 1984, Nair 1989). Nair (1989) found that calves were gradually trying to pluck grass from the second month onwards and were feeding on short blades of grass from the end of the fourth month, although their primary source of nutrition remained their mother's milk. A recent study on the early social behaviour of a captive Asian elephant calf at the Rosamond Gifford Zoo, USA found that the calf showed sucking behaviour soon after birth and adult-like feeding behaviour had not developed till at least four months of age, although the calf was observed to manipulate objects like leaves and taste them (Petraccione et al., 2017). African elephant calves become nutritionally self-sufficient only at 2 years of age, consuming mother's milk to a small extent even beyond 3 years of age (Lee and Moss 1986, Moss et al., 2011). Similarly, in a study conducted on semi-captive elephants of the Myanmar Timber Enterprise, it was found that calves were usually weaned between the ages of 4 and 5 years or sooner depending on the inter-birth interval (Mar et al., 2012). Since elephants are long-lived (see Sukumar 2003) and possibly learn various behaviours, motor tasks such as those involving walking probably develop faster than various behaviours. However, elephants also perform motor tasks with their trunk in addition to their limbs, and as the trunk is not required for immediate movement (nor is it used immediately after it is born - Nair 1989), it is possible that motor tasks using the trunk also develop gradually over a period of time. We, therefore, wanted to examine the development of trunk motor control and various behaviours in wild Asian elephant calves.

The trunk is very important for feeding, drinking, smelling, dusting, and use in social interactions. Behavioural lateralisation is thought to improve an animal's performance in foraging, predation, cognitive tasks and fear responses (Rogers 2002), and strong trunk lateralisation has previously been observed in individual adult Asian elephants (Martin and Niemitz 2003, Keerthipriya et al., 2015, Giljov et al., 2018). Trunk lateralisation was previously observed in juveniles also (Keerthipriya et al., 2015, Giljov et al., 2018) and even one two-month-old calf had shown strong trunk side preference (Keerthipriya et al., 2015). However, because of the small number of calves (less than one year old) sampled previously, the ontogeny of trunk lateralisation was not known. Owing to the novelty of feeding on vegetation, the possible practice required for using the trunk, and the possible lack of trunk strength at a young age, side preference in trunk movement could be expected to gradually develop from birth until the time calves feed primarily on grass. In the study of a single captive Asian elephant calf, the 
calf was able to perform an increasing number of complex and physically well-developed behaviours with age, suggesting that the expression of such skillful behaviours might be linked to physical maturity (Petraccione et al., 2017). However, it was also possible that, due to their precocial nature, maturation of trunk motor skills might occur early on and be manifest as early lateralisation of the trunk (as seen in the single two-month-old calf - Keerthipriya et al., 2015). Therefore, we wanted to examine the use of the trunk and development of side biases in trunk movement (see Fig. 1) with age in young elephants.

As mentioned above, since neonates of precocial mammals that have a long period of dependency on the mother may have a longer time for the development of various behaviours, we also wanted to examine the development of different kinds of behaviours (see Fig. 2) in this precocial but long-lived species with complex behaviours, in order to find out when adult-like behaviours emerged, whether there were differences in this timing based on behavioural categories (see Supplementary Figs. S1-4 and Supplementary Table 1), and to examine the extent of synchrony in behaviours between calves of different ages and their mothers. Synchronisation of activities can be costly when there are individuals with varying demands in a group, and this may lead to segregation between group members (Conradt 1998). However, segregation is not an option in the case of young ones that are dependent on the mother, leading to increased pressure for faster development of similar behaviours in the young as in adults and, hence, synchrony of behaviours.

We collected data on wild, individually identified elephants from Nagarahole and Bandipur National Parks and Tiger Reserves, referred to here as the Kabini elephant population, from December 2015-2017, in order to examine the development of trunk use and behaviours.

\section{Results}

\section{Trunk motor control and lateralisation}

We obtained data on trunk use from focal animal sampling, by video-recording calves ( $<1$ year old) or juveniles $(1-<5$ years old) and scoring the videos (see Methods). A total of 30 calves and juveniles, consisting of 16 females and 14 males, from 9 different clans, and ranging in age from $<1-29$ months, were sampled for examining trunk lateralisation of different kinds during 101 focal sessions for a total duration of $505.45 \mathrm{~min}$ (see Supplementary Table 2). Data were collected on 1) the numbers of times the focal individual used the trunk in clockwise and anticlockwise directions to pluck, gather, or grab vegetation or other objects successfully, 2) the numbers of times the focal individual attempted to move the trunk in clockwise and anticlockwise direction but did not successfully pluck vegetation or other objects, 3 ) the number of times the
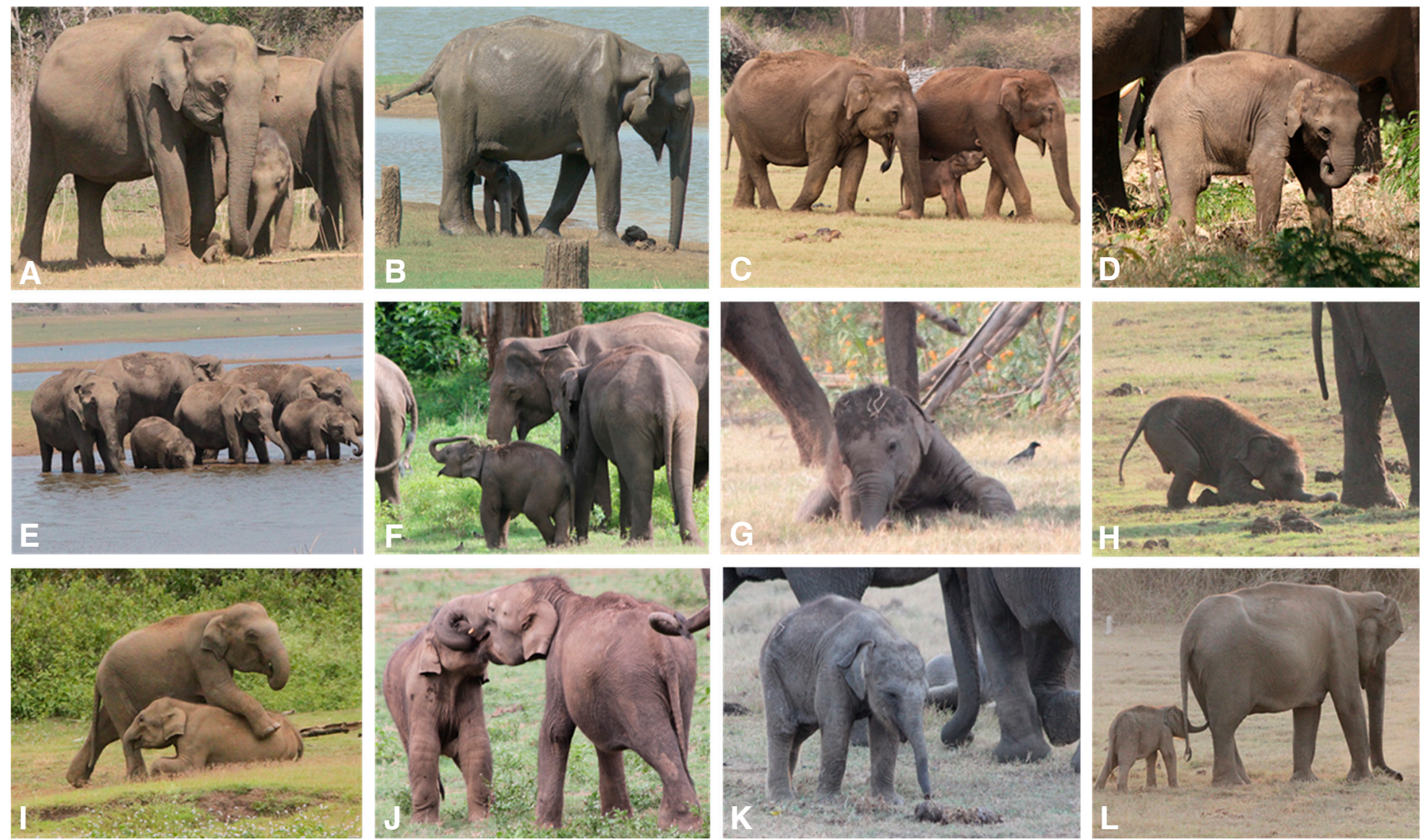

Fig. 2. Calves and juveniles of different age classes showing various behaviours. Feeding-related behaviours: (A) taking grass from a conspecific, (B) trying to locate the nipple in the wrong direction, (C) sucking from a non-mother conspecific, (D) chewing on grass, and (E) (calf on the left) drinking water using the mouth directly and (juvenile on the right) using the trunk to drink water. Grooming-related behaviours: (F) spraying dust/grass onto itself, (G) rolling in grass. Resting-related behaviour: (H) trying to sit down. Social interaction, play and exploration related behaviours: (I) climbing on a conspecific, (J) placing trunk tip in the mouth of a conspecific, (K) smelling dung, (L) checking a conspecific (see Supplementary Figs. S1-S4 and Supplementary Table 1 for more behaviour descriptions and photos). 
TABLE 1

\section{RESULTS OF MIXED-EFFECTS MODELS TO TEST THE EFFECTS OF AGE CLASS AND INDIVIDUAL IDENTITY ON THE LOGIT STRENGTHS OF DIFFERENT TYPES OF LATERALISATIONS AND ON THE LOGIT PROPORTION OF STRAIGHT TRUNK TOUCHES}

\begin{tabular}{|c|c|c|c|c|c|c|c|c|}
\hline Effect & Effect type & ss & $d f$ & MS & Den.Syn. Error $d f$ & Den.Syn. Error $M S$ & $\boldsymbol{F}$ & $\boldsymbol{P}$ \\
\hline \multicolumn{9}{|c|}{ Logit strength of lateralisation in successful trunk use (Mult. $R^{2}=0.792$, Adj. $R^{2}=0.535, P=0.003$ ) } \\
\hline Intercept & Fixed & 513.84 & 1 & 513.84 & 34.77 & 11.11 & 46.24 & $<0.001$ \\
\hline Individual ID & Random & 377.34 & 28 & 13.48 & 25.00 & 4.60 & 2.93 & 0.004 \\
\hline Age class & Fixed & 23.52 & 3 & 7.84 & 25.00 & 4.60 & 1.70 & 0.192 \\
\hline Error & & 114.98 & 25 & 4.60 & & & & \\
\hline \multicolumn{9}{|c|}{ Logit strength of lateralisation in unsuccessful trunk use (Mult. $R^{2}=0.616$, Adj. $R^{2}=0.091, P=0.352$ ) } \\
\hline Intercept & Fixed & 93.85 & 1 & 93.85 & 45.23 & 18.52 & 5.07 & 0.029 \\
\hline Individual ID & Random & 524.35 & 27 & 19.42 & 22.00 & 16.75 & 1.16 & 0.365 \\
\hline Age class & Fixed & 68.49 & 3 & 22.83 & 22.00 & 16.75 & 1.36 & 0.280 \\
\hline Error & & 368.57 & 22 & 16.75 & & & & \\
\hline \multicolumn{9}{|c|}{ Logit proportion of unsuccessful trunk use (Mult. $R^{2}=0.728$, Adj. $R^{2}=0.357, P=0.053$ ) } \\
\hline Intercept & Fixed & 29.07 & 1 & 29.07 & 45.78 & 3.64 & 7.98 & 0.007 \\
\hline Individual ID & Random & 101.38 & 27 & 3.75 & 22.00 & 3.42 & 1.10 & 0.416 \\
\hline Age class & Fixed & 57.89 & 3 & 19.30 & 22.00 & 3.42 & 5.64 & 0.005 \\
\hline Error & & 75.26 & 22 & 3.42 & & & & \\
\hline \multicolumn{9}{|c|}{ Logit proportion of straight trunk touches (Mult. $R^{2}=0.773$, Adj. $R^{2}=0.463, P=0.015$ ) } \\
\hline Intercept & Fixed & 118.84 & 1 & 118.84 & 41.81 & 2.03 & 58.68 & $<0.001$ \\
\hline Individual ID & Random & 62.51 & 27 & 2.32 & 22.00 & 1.46 & 1.59 & 0.135 \\
\hline Age class & Fixed & 45.10 & 3 & 15.03 & 22.00 & 1.46 & 10.32 & $<0.001$ \\
\hline Error & & 32.04 & 22 & 1.46 & & & & \\
\hline \multicolumn{9}{|c|}{ Logit strength of lateralisation in mouth placement (Mult. $R^{2}=0.489$, Adj. $R^{2}=-0.185, P=0.794$ ) } \\
\hline Intercept & Fixed & 111.01 & 1 & 111.01 & 45.11 & 17.46 & 6.36 & 0.015 \\
\hline Individual ID & Random & 391.29 & 26 & 15.05 & 22.00 & 25.78 & 0.58 & 0.905 \\
\hline Age class & Fixed & 40.96 & 3 & 13.65 & 22.00 & 25.78 & 0.53 & 0.667 \\
\hline Error & & 567.09 & 22 & 25.78 & & & & \\
\hline \multicolumn{9}{|c|}{ Logit strength of lateralisation in body touch (Mult. $R^{2}=0.571$, Adj. $R^{2}=-0.006, P=0.519$ ) } \\
\hline Intercept & Fixed & 567.75 & 1 & 567.75 & 46.43 & 12.70 & 44.72 & $<0.001$ \\
\hline Individual ID & Random & 358.02 & 28 & 12.79 & 23.00 & 12.49 & 1.02 & 0.482 \\
\hline Age class & Fixed & 48.99 & 3 & 16.33 & 23.00 & 12.49 & 1.31 & 0.296 \\
\hline Error & & 287.20 & 23 & 12.49 & & & & \\
\hline
\end{tabular}

Significant $P$ values are shown in bold.

focal individual touched the ground straight, without curling the tip of the trunk, 4) the number of times vegetation or other objects were placed on the right or left side of the mouth, and 5) and the number of times the individual touched the right or left side of its body (see Fig. 1), and the direction of side preference was measured using the lateral bias index (Bard et al., 1990; see Methods). The strength of lateralisation was obtained as the absolute value of the lateral bias index (see Methods). We expected trunk side preferences to increase with age when the trunk was used in the context of feeding but not in the context of body touches.

Since these datasets included repeated observations on the same individuals within age classes, we carried out repeated measures ANOVAs on the logit proportion of clockwise (successful or unsuccessful) trunk movement by the same individuals, across days but within the same age class (using sex and age class as categorical factors), and found that these did not change across the repeat samples (see Supplementary Tables 3-7). The same was true when repeated measures ANOVAs were carried out on the logit proportions of right side trunk placement in mouth, and right side body touch, and was only of borderline significance when straight trunkmovement was examined (see Supplementary Tables 3-7). Thus, there was consistency within individuals sampled within an age class. We, therefore, carried out the subsequent analyses using subsets of the different datasets (successful trunk movement, unsuccessful trunk movement, straight trunk touch, trunk placement in the mouth, and body touch), in which each individual was represented only once in a particular age class $(<3,3-6,6-12$, and >12 months; see Methods).

We found overall significant side preference in successful trunk use in 87 of the 94 sessions in which successful trunk use was observed (92.6\%; 52 out of 57 (91.2\%) sessions with each individual being represented only once in an age class; significance based on binomial tests, $P<0.05)$. Significant side preference was lower when there was unsuccessful trunk use, with significant side preference observed in 55 out of 79 such sessions (69.6\%; 42 out of $53(79.2 \%)$ sessions with each individual being represented only once in an age class; significance based on binomial tests, $P<0.05$ ). Significant side preference in mouth placement was seen only in 41 out of 85 sessions (48.2\%; 20 out of 52 (38.5\%) sessions with each individual being represented only once in an age class) and significant side preference in body touch was seen only in 26 out of 89 sessions (29.2\%; 13 out of 55 (23.6\%) sessions with each individual being represented only once in an age class). Thus, the lateral bias index of trunk use was different from zero in most of the cases, while the lateral bias index of trunk placement in the mouth and body touch were largely zero (Fig. 3). The average (across 53 sessions with each individual being represented only once in an age class) proportion of straight trunk touches with no directionality was $27.8 \%$.

Visual inspection of the lateral bias index based on success- 
ful trunk use across age classes showed the greatest proportion of unlateralised individuals in the $<3$ months age class (Fig. 4). The proportion of unlateralised individuals decreased across age classes until all individuals over 12 months of age were completely lateralised in successful trunk use. A similar pattern was seen in unsuccessful trunk use, but individuals over 12 months of age also showed a lateral bias index of zero in this category (Fig. 4). However, this must be read along with the finding that the total proportion of unsuccessful trunk use itself decreased with age (Fig. 5). The frequency distribution of the proportion of straight touches shifted towards the left with increasing age class, with older individuals showing a smaller proportion of straight touches (Fig. 4, 5).

We used mixed-effects models (with age class as the fixed factor and individual identity as random factor) to statistically examine the effect of age class on the strengths of lateralisation (the absolute values of the lateral bias index) and proportion of straight trunk touches. Although we could see a small trend with age class in lateral bias indices of successful and unsuccessful trunk use, there was no effect of age class on the logit strengths of lateralisation in successful or unsuccessful trunk use, in mouth placement, or in body touches (Table 1), probably because many of the calves less than 3 months old already showed significant lateralisation (Fig. 4). There was an effect of individual identity on the lateralisation in successful trunk use but not on the other dependent variables.

However, there was a significant effect of age class on the logit proportions of unsuccessful trunk movements (although this had a borderline non-significant adjusted whole model $R^{2}$ ) and straight trunk touches, with decreasing proportions of both with increasing age (see Table 1, Fig. 6). Post hoc Tukey's HSD tests showed the same patterns of differences across age classes in both variables. The logit proportions of unsuccessful trunk movements and straight trunk touches of $<3$-month-old and 3-6-monthold calves were significantly higher than those of $>12$-month-old juveniles (Tukey's HSD tests: logit proportion of unsuccessful trunk movements: <3-month-old and >12-month old calves/juveniles: $P<0.001$; 3-6-month-old and $>12$-month old calves/juveniles: $P=0.025$; logit proportion of straight trunk touches: $<3$-month-old and $>12$-month old calves/juveniles: $P<0.001$; 3-6-month-old and $>12$-month old calves/juveniles: $P=0.002$ ). The logit proportions

A

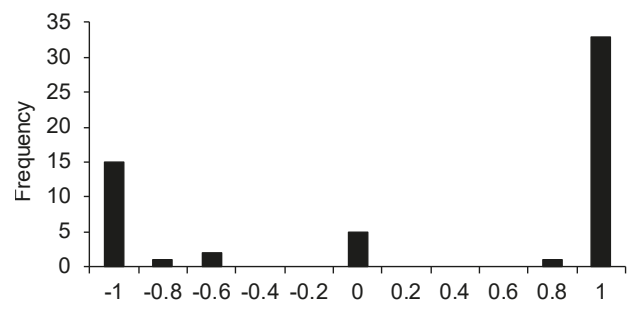

B

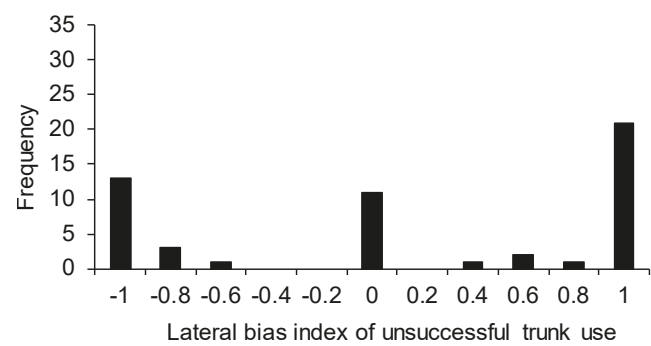

Lateral bias index of unsuccessful trunk use
C
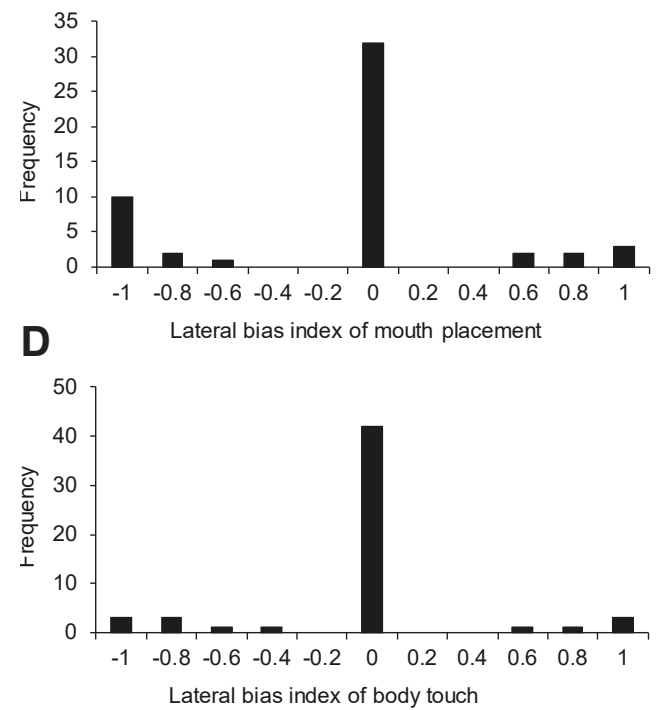

TABLE 2

\section{NUMBER OF SCAN SAMPLES USED TO OBTAIN DATA ON BEHAVIOURAL STATES AND THE AGE CLASS AND SEX OF INDIVIDUALS SAMPLED}

\begin{tabular}{lccc} 
& \multicolumn{3}{c}{ No. of scans for behaviour sampling } \\
\cline { 2 - 4 } Age class (in years) & Scans on males & Scans on females & Total \\
\hline$<0.25$ & 70 & 61 & 131 \\
$0.25-0.5$ & 64 & 79 & 143 \\
$0.5-1$ & 17 & 48 & 65 \\
$1-1.5$ & 16 & 45 & 61 \\
$1.5-2$ & 2 & 26 & 28 \\
$2-3$ & 26 & 41 & 67 \\
$3-5$ & 26 & 35 & 61 \\
$5-10$ & 142 & 241 & 383 \\
$10-15$ & 95 & 392 & 487 \\
$15-20$ & 22 & 184 & 206 \\
$20-30$ & 16 & 221 & 237 \\
$30-40$ & 8 & 208 & 216 \\
$40-50$ & 1 & 203 & 204 \\
$50-60$ & 3 & 148 & 151 \\
$60-65$ & 0 & 53 & 53 \\
\hline Total & 508 & 1985 & 2493 \\
\hline
\end{tabular}

of unsuccessful trunk movements and straight trunk touches of $<3$-month-old calves were also significantly higher than those of 6-12-month-old calves (logit proportion of unsuccessful trunk movements: $P=0.011$; logit proportion of straight trunk touches: $P=0.015)$, but those of $<3$-month-old and 3-6 month-old calves were not significantly different from each other (logit proportion of unsuccessful trunk movements: $P=0.073$; logit proportion of straight trunk touches $P=0.412$ ). The logit proportions of unsuccessful trunk movements and straight trunk touches of 3-6-month old calves and 6-12-month-old calves, and 6-12-month-old calves and $>12$-month-old juveniles were also not significantly different from each other (Tukey's HSD tests: logit proportion of unsuccessful trunk movements: 3-6-month old and 6-12-month-old calves: $P=0.523$; 6-12-month-old and $>12$-month-old calves/juveniles: $P=0.433$; logit proportion of straight trunk touches: 3-6-month old and 6-12-month-old calves: $P=0.192 ; 6-12$-month-old and >12-month-old calves/juveniles: $P=0.292$; Fig. 6). 
Though we found a negative correlation between the strength of successful trunk movements and the proportion of unsuccessful trunk movements and between the strength of successful trunk movements and the proportion of straight trunk touches,

We examined the correlation between the strength of side bias in successful trunk movements and the proportion of unsuccessful trunk movements and found a negative correlation (Pearson's $R=$ $-0.43, P<0.05, R^{2}=0.184$, Spearman's $R=-0.167$, $P>0.05$, see Fig. 7 ), but the value of the correlation was small. Similarly, we also found a small, negative correlation between the strength of side bias in successful trunk movements and the proportion of straight trunk touches, but only using parametric correlations (although the data were non-normal) (Pearson's $R=-0.45, P<0.05, R^{2}=0.201$, Spearman's $R=-0.264, P>0.05$, see Fig. 7).

\section{Behaviour}

\section{Activity budget and age}

Analyses on activity states were carried out on data collected through scan sampling (see Methods) from February to December 2016 (see Table 2 for sample sizes and age-sex classes sampled). Scan samples from 69 days, collected on 68 unique males and 168 unique females (236 in all), were used to analyse behavioural data. Focal samples on 30 unique calves, of which 16 were males and 14 were females, from 11 different clans, collected from Janu- ary 2016 to November 2017, were used for fine-scale analyses of various calf behaviours. These calves were from 11 different clans (see Table 3 for sample sizes and age-sex classes sampled). We recorded a total of 81 different calf behaviours which were classified into four behavioural classes: a) feeding, b) grooming, c) resting, and d) social interaction, play and exploration related behaviours (see Supplementary Figs. S1-4 and Supplementary Table 1).

We used scan sampling data to construct activity budgets for individuals of different age classes and found that the proportion of time (scans) individuals spent feeding increased with age until about 2 years of age, after which it was roughly the same (Fig. 8). The proportion of time spent resting similarly decreased, being the maximum in calves below six months of age, followed by calves up to 1 year of age (Fig. 8).

We used the focal animal sampling data on calves to examine behaviour at a fine scale (second-by-second data scoring). The second-by-second scoring of focal videos for a total duration of $774.38 \mathrm{~min}$ showed that the behaviours displayed by calves lasted for short durations (average \pm 1.96 SE duration of a behaviour: $14.00 \pm 1.25$ seconds; number of behavioural actions scored: 3221 ) and thus changed rapidly. The minimum and maximum durations taken to complete a behaviour were 1 second and 600 seconds, respectively. The average $( \pm 1.96 \mathrm{SE})$ duration of feeding behaviours was $21.7( \pm 2.25)$ seconds, that of grooming behaviours

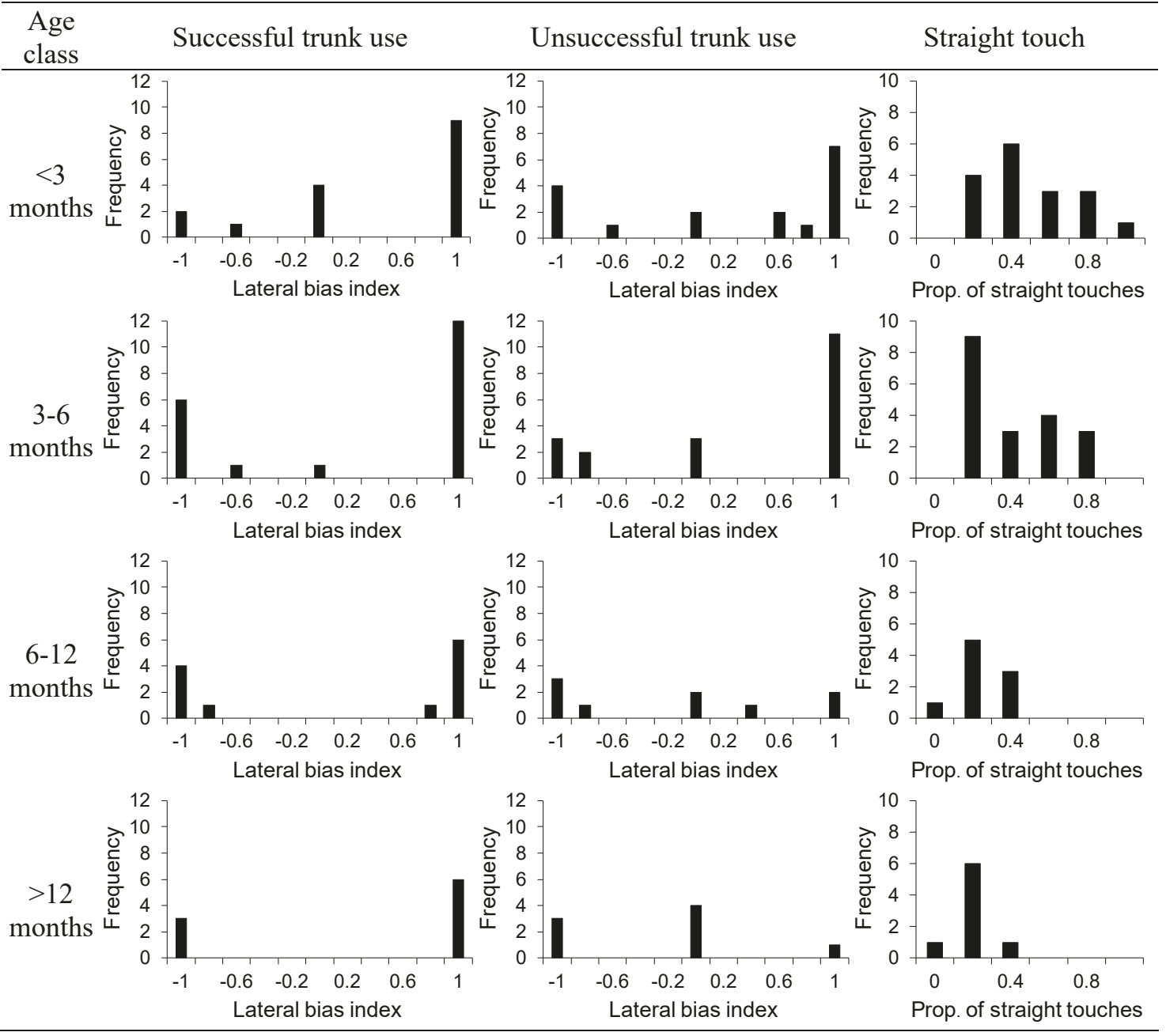

Fig. 4. Frequency distributions of lateral bias indices calculated from successful and unsuccessful trunk use and of the proportion of straight touches, for individuals of different age classes. Individuals that did not exhibit significant lateral bias have been shown to have a lateral bias index value of zero. 
TABLE 3

\section{NUMBER OF FOCAL SESSIONS AND FOCAL DURATION OF INDI- VIDUALS OF DIFFERENT AGE-SEX CLASSES}

\begin{tabular}{lcccccc}
\multirow{2}{*}{$\begin{array}{l}\text { Age class } \\
\text { (months) }\end{array}$} & \multicolumn{2}{c}{ Number of focal sessions } & \multicolumn{3}{c}{ Focal duration (in min) } \\
\cline { 2 - 7 } & Males & Females & Total & Males & Females & Total \\
\hline$<3$ & 12 & 11 & 23 & 179.92 & 165.57 & 345.48 \\
$3-6$ & 7 & 8 & 15 & 107.35 & 121.72 & 229.07 \\
$6-12$ & 4 & 9 & 13 & 61.22 & 138.62 & 199.83 \\
\hline
\end{tabular}

was $8.5( \pm 1.61)$ seconds, that of resting behaviours was $17.8( \pm$ 3.96) seconds, and that of social interactions, play and exploration behaviours was $6.2( \pm 0.48)$ seconds.

Of the 3221 behavioural actions by calves that we observed, $71 \%$ of the behaviours lasted for less than or equal to $10 \mathrm{sec}-$ onds. However, despite the short duration of calf actions, the proportion of scans (which are usually meant to recover relatively long 'states') spent in different behavioural classes were not very different from those based on focal sampling. The proportion of time spent on feeding-related behaviours was 0.48 based on the scans compared to 0.52 based on focal animal sampling, that spent on social interactions, play and exploration was 0.15 based on scans compared to 0.14 based on focal animal sampling, and that spent on grooming-related behaviours was 0.02 based on scans compared to 0.07 based on focal animal sampling. The proportion of time spent on resting-related behaviours seemed to be greater (average $=0.35$ ) based on scans than based on focal animal sampling (average=0.27). A General Linear Model (GLM) to examine the effects of age-class and behavioural class of calf action (fixed factors) and calf identity (random factor) on behaviour duration showed no significant effect of age-class $\left(F_{2,181}=1.658\right.$, $P=0.193)$, behavioural class of calf action $\left(F_{3,181}=1.986, P=0.118\right)$ or interaction between age class and behavioural class of calf action $\left(F_{6,181}=1.490, P=0.184\right)$ (see Supplementary Fig. S5).

We ran a GLM with age-class and behavioural class of calf action as fixed factors and calf identity as a random factor to find out how these affected calf behaviour. While there was no significant main effect of age class $\left(F_{2,199}=0.278, P=0.758\right)$, there were significant effects of behavioural class $\left(F_{3,199}=27.265, P<0.001\right)$ and interaction between age class and behavioural class $\left(F_{6,199}=8.090, P<0.001\right)$ on the logit proportion of time spent in various behaviours. Post hoc Tukey's HSD tests showed that calves spent a significantly higher proportion of time in feeding related activities (average \pm 1.96 SE proportion of time: $0.461 \pm 0.082$ ) than in grooming related
A
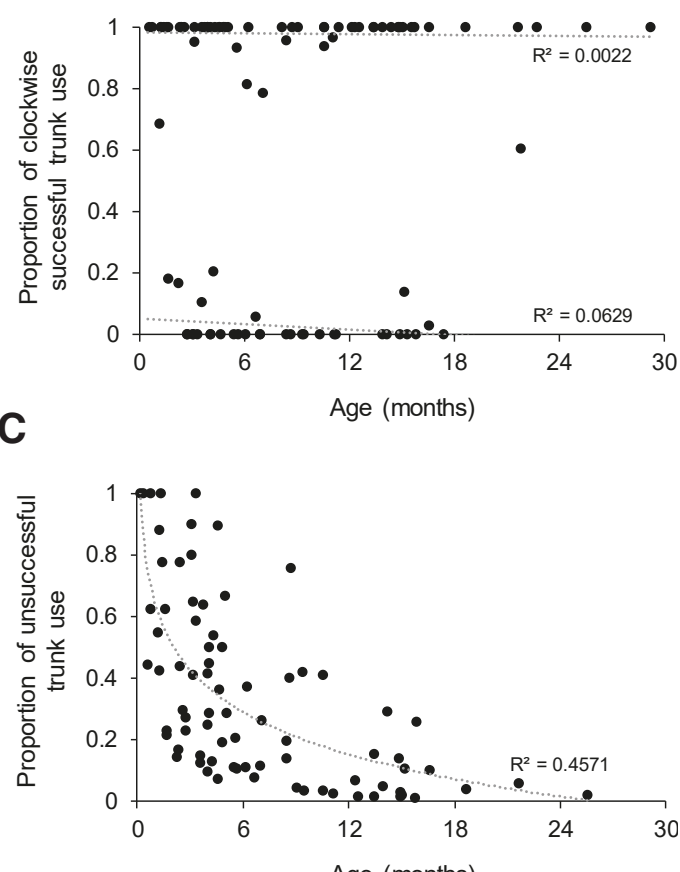

E

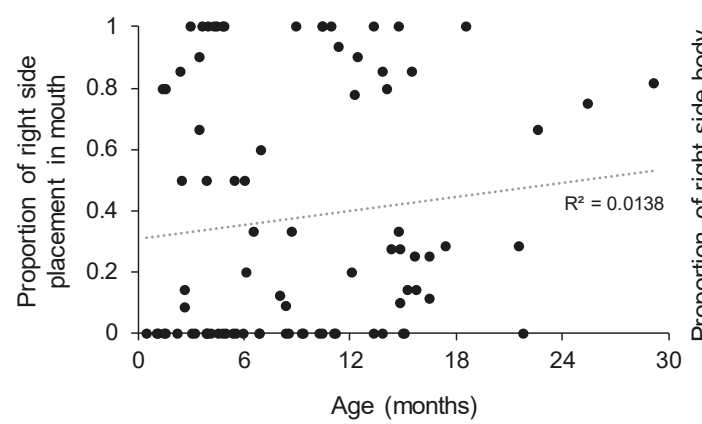

B
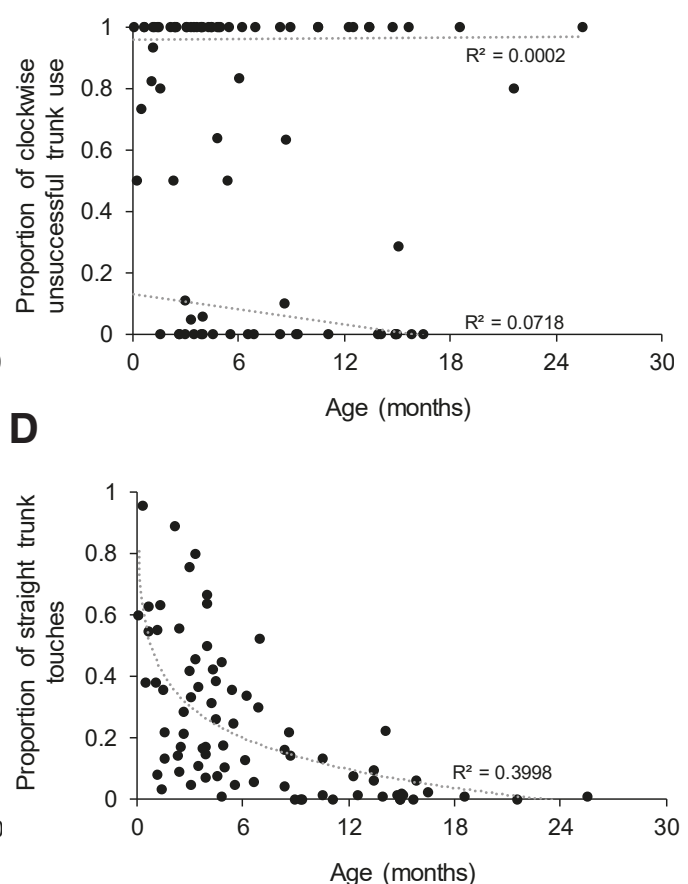

$\mathbf{F}$

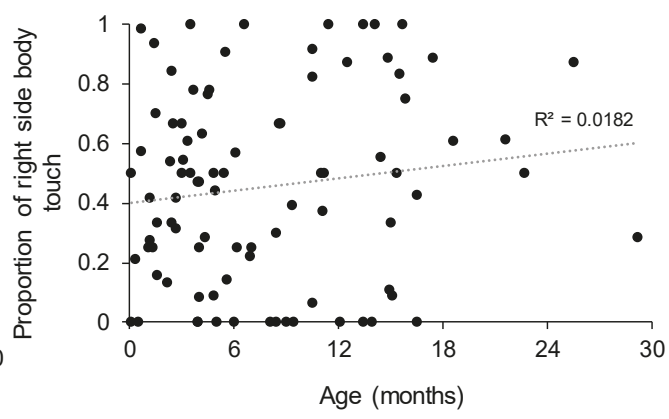

Fig. 5. Ontogeny of trunk motor control and laterality. Proportions of (A) clockwise successful trunk use, (B) clockwise unsuccessful trunk use, (C) unsuccessful trunk use (calculated as the ratio of unsuccessful - clockwise and anticlockwise - movements divided by the total number of unsuccessful and successful trunk movements), (D) straight trunk touches (calculatedas the ratio of the number of straight trunk touches divided by the total number of trunk movements, including straight touches, successful, and unsuccessful movements), (E) right side placement of the trunk in the mouth, and (F) right side body touch using the trunk, with increasing age. Regression lines (logarithmic regressions in the case of $(C, D)$ are shown along with $\mathrm{R}^{2}$ values. Regression lines are drawn separately for the clockwise and anticlockwise movements in panels $(A, B)$. 

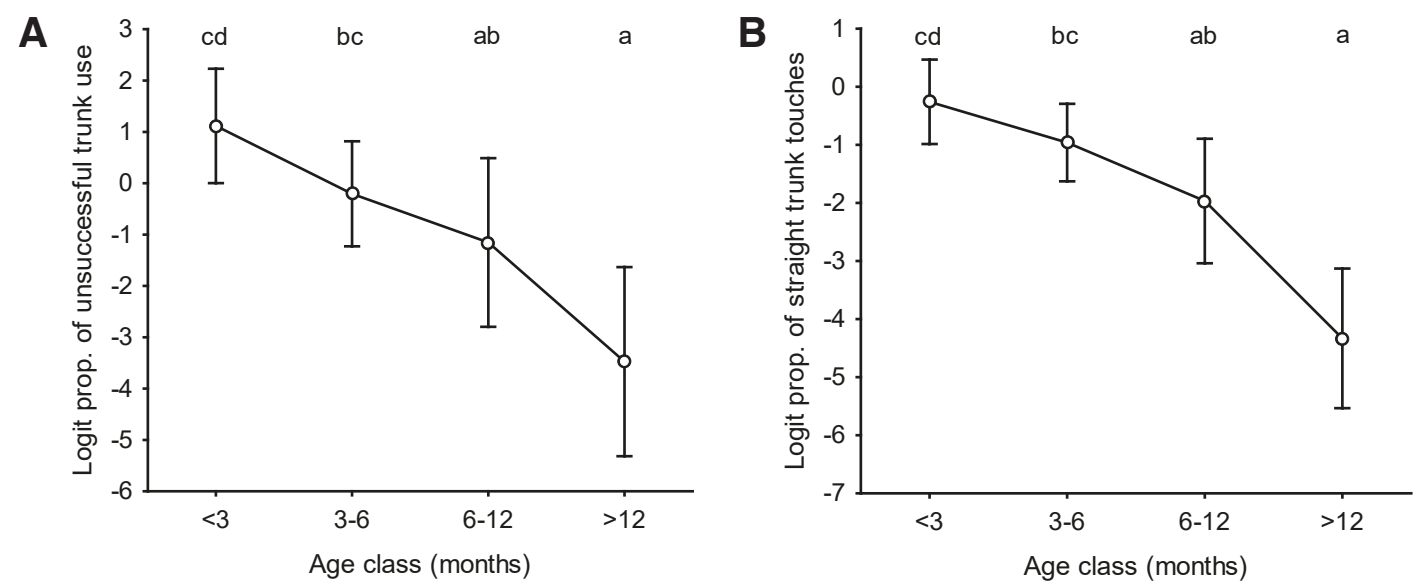

Fig. 6. Effect of age on unsuccessful and unlateralised trunk use. The logit proportion of (A) unsuccessful trunk use lout of successful and unsuccessful trunk use) and (B) straight trunk touches (out of successful and unsuccessful trunk movements and straight touches) shown by calves/ juveniles of different age classes. Results of post hoc tests are shown as alphabets at the top of the graph: $a<b<c<d$ and shared alphabets indicate non-significant comparisons. Error bars are $95 \% \mathrm{Cl}$. The untransformed proportions corresponding to the four logit proportions in (A) are $0.781,0.413$, 0.197 , and 0.055 , respectively, and in (B) are 0.387, 0.249, 0.105, and 0.036, respectively.

activities (average $\pm 1.96 \mathrm{SE}: 0.079 \pm 0.030 ; P<0.001$ ) and in social interactions, play, and exploration related activities (average \pm 1.96 SE: $0.141 \pm 0.032 ; P<0.001$ ), but the time spent in feeding related activities was not significantly different from that spent in resting related activities (average $\pm 1.96 \mathrm{SE}: 0.318 \pm 0.080 ; P=0.402$ ). Post hoc Tukey's HSD tests also showed that the logit proportion of time spent in feeding by <3-month-old calves (average \pm 1.96 SE proportion of time: $0.292 \pm 0.096$ ) was significantly lower than that spent by $6-12$-month-old calves (average $\pm 1.96 \mathrm{SE}: 0.740$ $\pm 0.130 ; P<0.001$ ), but was not significantly different from that of 3-6-month-old calves (average \pm 1.96 SE: $0.521 \pm 0.146 ; P=0.340$; see Fig. 9). There was no significant difference in the logit proportion of time spent in feeding between 3-6-month-old and 6-12-monthold calves $(P=0.860)$. The logit proportion of time spent resting by $<3$-month-old calves (average \pm 1.96 SE proportion of time: 0.460 \pm 0.119 ) was significantly higher than that spent by 6 - 12 -month-old calves (average \pm 1.96 SE: $0.101 \pm 0.086 ; P<0.001$ ) but was not significantly different from that of 3-6-month-old calves (average \pm 1.96 SE: $0.252 \pm 0.134 ; P=0.203$ ), and there was no significant difference in the logit proportion of time spent in resting between 3-6-month-old and 6-12-month-old calves ( $P=0.870$; see Fig. 9). There was no significant difference between any of the age classes in the logit proportion of time spent in grooming and social interactions, play and exploration related activities.

A

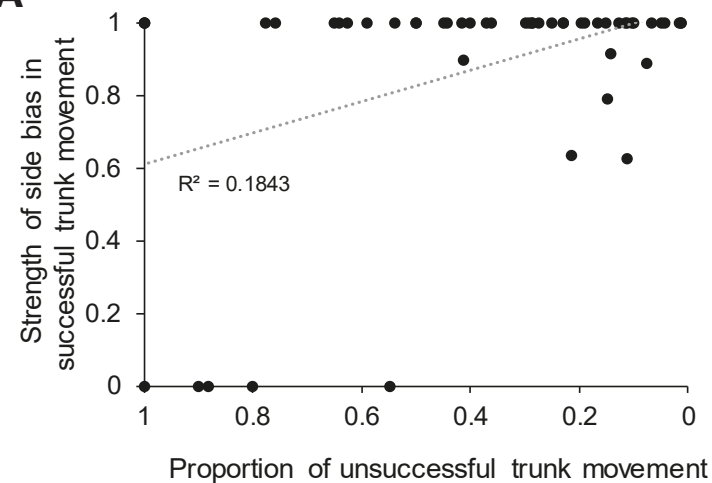

We further wanted to check if there was any difference in the proportion of time spent in different behavioural classes within the first three months after birth. Hence, we divided calves into four age classes: $<1$ month, 1-2 months, $2-3$ months, and $>3$ months of age and carried out the GLM as described above. We found no significant main effect of age class again $\left(F_{3,195}=0.148, P=0.931\right)$. Although there was a significant main effect of behavioural class $\left(F_{3,195}=19.998, P<0.001\right)$ and a significant interaction effect between age class and behavioural class $\left(F_{9,195}=4.704, P<0.001\right)$, Tukey's HSD tests did not show a significant difference between any pair of the age classes within 3 months of age for any of the behavioural classes.

\section{Behavioural stages and age}

Based on the level of competence of behavioural execution by a calf and when the behaviour was normally shown, we classified the 81 calf behaviours observed into four behavioural stages: a) preparatory calf behaviour, b) preparatory adult behaviour, c) calfspecific behaviour, and d) adult-like behaviour (see Materials and Methods, Supplementary Figs. S1-4 and Supplementary Table 1). Preparatory calf behaviours were seen only in the context of feeding behaviours, and preparatory adult behaviours were seen in all behavioural classes except for grooming, which had only calf-specific (and only a single such behaviour, seen only once in
B

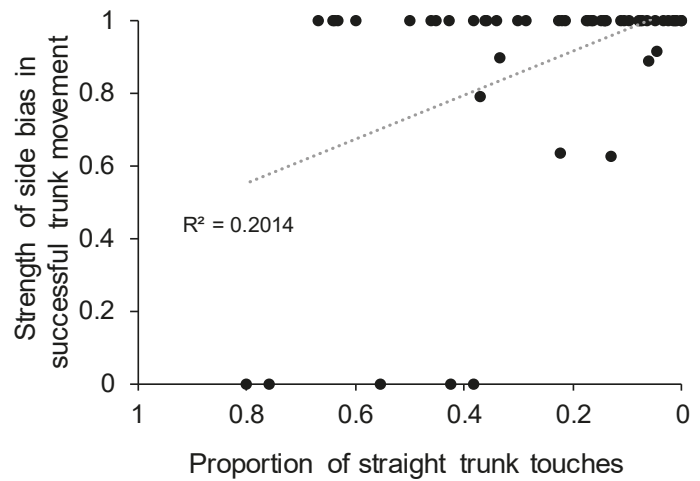

Fig. 7. Strength of side preference in successful trunk movement and trunk motor ability in terms of (A) proportion of unsuccessful trunk movement and (B) proportion of straight trunk touches. The $x$-axes are reversed as the proportions decrease with increasing age. 


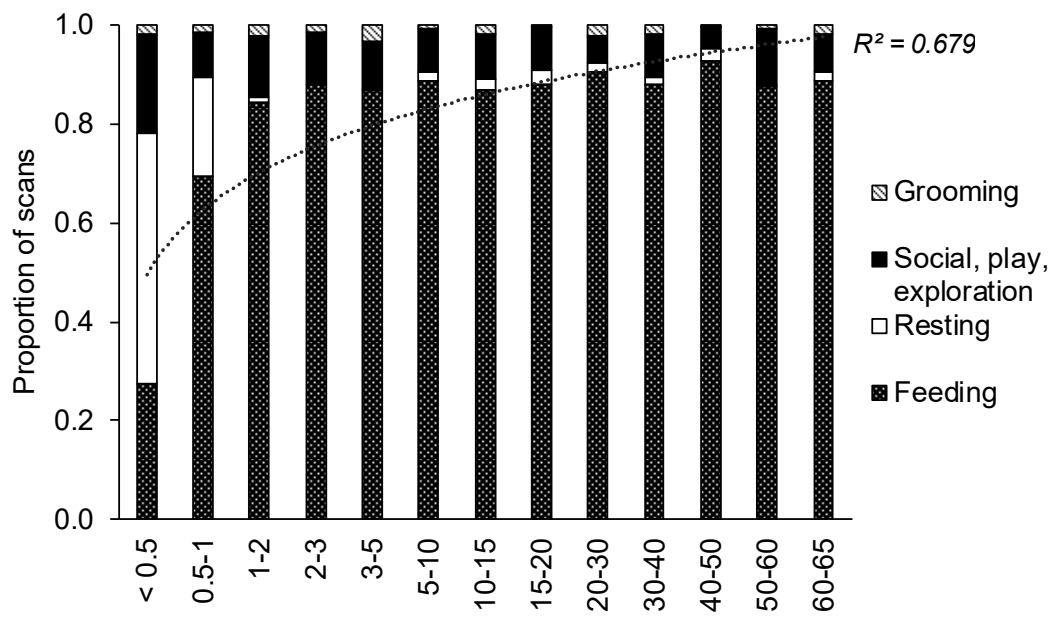

Age class (years)

the field) and adult-like behaviours (Fig. 10).

We ran a GLM on the logit proportion of time spent by calves in showing preparatory behaviours (preparatory calf and preparatory adult combined as preparatory calf behaviour was seen only in the context of the initial sucking from the mother), using age class and behavioural class as fixed factors and calf identity as a random factor. Age class did not have a significant effect on the proportion of time spent by calves in showing preparatory behaviours $\left(F_{2,181}=0.761\right.$, $P=0.469$ ), but there was a significant main effect of behavioural class $\left(F_{3,181}=437.817, P<0.001\right)$ and a significant interaction effect between age class and behavioural class $\left(F_{6,181}=3.977, P=0.001\right)$. The logit proportion of time spent in preparatory behaviours was higher in feeding-related behaviours (average $\pm 1.96 \mathrm{SE}$ proportion of time: $0.543 \pm 0.088$ ) than in resting-related behaviours (average \pm 1.96 SE proportion of time: $0.002 \pm 0.002 ; P<0.001$ ) or social

Age class*Behavioural class; LS Means Current effect: $F(6,--)=8.0896, P<0.001$ Vertical bars denote $95 \% \mathrm{Cl}$

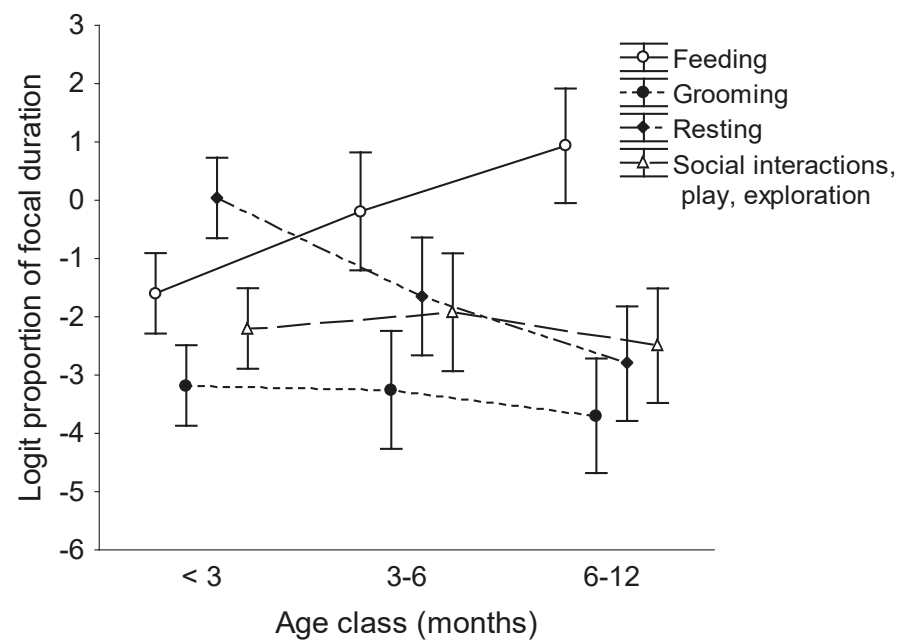

Fig. 8. Proportion of scans during which individuals of different age classes showed different classes of behaviour. The trendline shown is for the proportion of scans spent in feeding behaviour and is a logarithmic fit given by the equation $y=0.1866 \ln (x)+0.4962$

interaction, play and exploration-related behaviours (average \pm 1.96 SE proportion of time: $0.003 \pm 0.003$; $P<0.001)$. There was no significant difference between the behavioural classes resting and social interactions, play and exploration in the proportion of time spent in preparatory behaviours. Calves $<3$ months of age showed a higher logit proportion of time in preparatory feeding behaviour (average $\pm 1.96 \mathrm{SE}$ proportion of time: 0.741 \pm 0.111 ) than calves $3-6$ months of age (average \pm 1.96 SE proportion of time: $0.400 \pm 0.159$; Tukey's HSD test, $P<0.001)$ and calves 6-12 months of age (average \pm 1.96 SE proportion of time: $0.346 \pm 0.119 ; P<0.001$, Fig. 11). There was no significant difference in the time spent in preparatory feeding behaviour between calves of 3-6 and 6-12 months of age $(P=1.000)$. There were also no significant differences across age classes in the logit proportions of time spent in preparatory behaviours under the grooming, resting, or social interactions categories (see Fig. 11). GLM using the four age classes - $<1$ month, 1-2 months, 2-3 months, and $>3$ months - showed significant effects of age class $\left(F_{3,177}=5.033, P=0.002\right)$, behavioural class $\left(F_{3.177}=461.583, P<0.001\right)$, and interaction of the two $\left(F_{9177}=4.117, P<0.001\right)$, but post hoc Tukey's HSD tests did not yield any significant difference in the logit proportions of time spent in preparatory behaviours of any behavioural class between any pair of the age classes within 3 months of age.

We ran a GLM on the logit proportion of time spent by calves in showing adult-like behaviours also, as with the one on preparatory behaviours above. There were significant effects of age class $\left(F_{2,181}=11.213, P<0.001\right)$, behavioural class $\left(F_{3,181}=110.696\right.$, $P<0.001)$, and interaction between these two factors $\left(F_{6,181}=26.016\right.$, $P<0.001)$ on the logit proportion of time calves showed adult-like behaviours. The logit proportion of time spent in adult-like behaviours by calves $<3$ months of age (average \pm 1.96 SE proportion

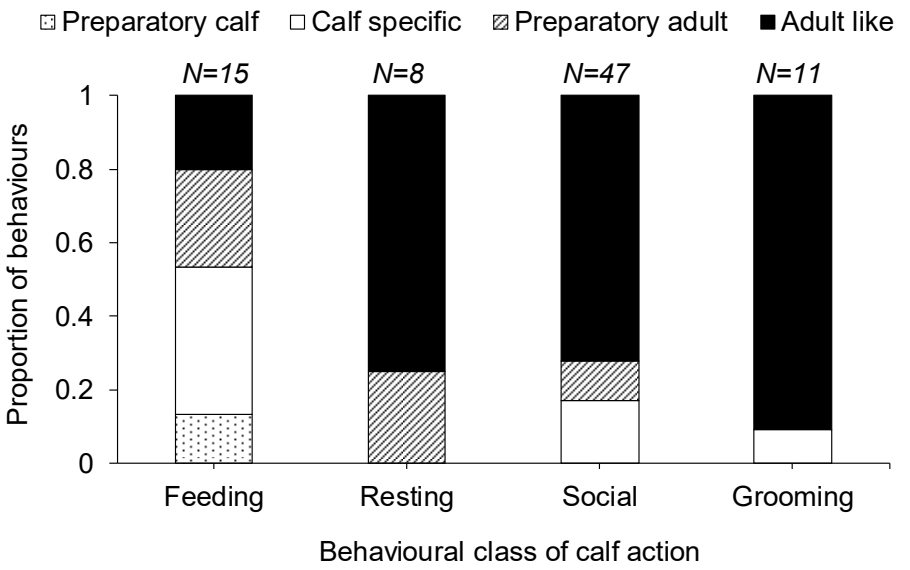

Fig. 9 (left). Proportion of focal duration spent in feeding, grooming, resting, and social interactions, play and exploration related behaviours by calves of different age classes. Error bars are $95 \% \mathrm{Cl}$.

Fig. 10 (right). Proportion of unique calf behaviours belonging of different behavioural stages. Preparatory calf behaviour, calf-specific behaviour, preparatory adult behaviour, and adult-like behaviour under different behavioural classes: (1) feeding, (2) resting, (3) social interaction, play and exploration, and (4) grooming related behaviours. $\mathrm{N}$ is the number of unique behaviours in that behavioural class. 
of time: $0.716 \pm 0.077$ ) was significantly lower than that shown by calves 3-6 months of age (average \pm 1.96 SE proportion of time: $0.826 \pm 0.077$; Tukey's HSD test: $P<0.001)$ and $6-12$ months of age (average $\pm 1.96 \mathrm{SE}$ proportion of time: $0.857 \pm 0.064 ; P<0.001$ ), and the latter two age classes did not significantly differ from each other $(P=0.759)$. The logit proportion of time spent in adult-like behaviours by calves under the behavioural class feeding (average \pm 1.96 SE proportion of time: $0.333 \pm 0.092$ ) was significantly lower than those spent under grooming (average \pm 1.96 SE proportion of time: $1.000 \pm 0.00 ; P<0.001$ ), resting (average \pm 1.96 SE proportion of time: $0.987 \pm 0.011 ; P<0.001$ ), and social interaction, play and exploration behavioural classes (average \pm 1.96 SE proportion of time: $0.800 \pm 0.068 ; P<0.001)$. The logit proportion of time spent in adult-like behaviours by calves under the behavioural class grooming was significantly higher than that spent under social interactions, play, exploration $(P<0.001)$ but was not significantly different from that under resting $(P=0.899)$. The proportion of time spent in adult-like behaviours by calves under the behavioural class resting was higher than that spent under social interactions, play, exploration $(P<0.001)$. The logit proportion of time spent in adult-like behaviours under the behavioural class feeding by calves under 3 months of age (average \pm 1.96 SE proportion of time: $0.078 \pm$ 0.074 ) was significantly lower than that by calves of 3-6 months of age (average \pm 1.96 SE proportion of time: $0.516 \pm 0.174 ; P<0.001$ ) and $6-12$ months of age (average \pm 1.96 SE proportion of time:
$0.591 \pm 0.130 ; P<0.001)$, while there was no significant difference between calves of 3-6 and 6-12 months of age ( $P=0.930$; see Fig. 11). There was also no significant difference between the proportions of time spent in adult-like behaviours between any of the three age classes under each of the other behavioural classes (Fig. 11).

Like the preparatory behaviours, we also looked at the logit proportion of time spent in adult-like behaviours by calves within 3 months of age. Although there were significant effects of age class $\left(F_{3,177}=7.776, P<0.001\right)$, behavioural class $\left(F_{3,177}=206.966\right.$, $P<0.001)$, and interaction between these two factors $\left(F_{9,177}=18.592\right.$, $P<0.001)$ on the logit proportion of time spent in adult-like behaviours by calves, Tukey's HSD tests were not significant between any pair of the age classes within 3 months of age.

\section{Behavioural synchrony}

We calculated the behavioural-class synchrony between calves/juveniles and their mothers, with synchrony being 1 if the calf/juvenile and its mother showed behaviours belonging to the same behavioural class during a particular scan, and synchrony being 0 if they showed behaviours belonging to different behavioural classes. Based on generalized linear mixed-effects models with synchrony as a binomial dependent variable, age of the calf/ juvenile, and behavioural class as fixed factors, and identities of the mother and calf/juvenile as random factors (see Methods), we found the best model explaining synchrony to include calf age

TABLE 4

\begin{abstract}
RESULTS OF GENERALIZED LINEAR MIXED-EFFECTS MODELS WITH SYNCHRONY IN BEHAVIOURAL CLASS BETWEEN MOTHER AND OFFSPRING (“CALF” IN THIS TABLE AND THE NEXT INCLUDES CALVES AND JUVENILES) AS THE BINOMIAL DEPENDENT VARIABLE, CALF AGE AND BEHAVIOURAL CLASS AS FIXED FACTORS, AND IDENTITIES OF THE CALF/JUVENILE AND MOTHER AS RANDOM FACTORS
\end{abstract}

\begin{tabular}{|c|c|c|c|c|c|}
\hline \multirow[b]{2}{*}{ Model } & \multicolumn{2}{|c|}{ No. of parameters } & \multirow[b]{2}{*}{ AIC } & \multirow[b]{2}{*}{$\Delta \mathbf{A I C}$} & \multirow[b]{2}{*}{ Deviance } \\
\hline & Fixed & Random & & & \\
\hline Synchrony $\sim 1+$ Calf age + Behavioural class & 2 & - & 249.94 & 0 & 239.94 \\
\hline Synchrony $\sim 1+$ Calf age + Behavioural class + Sex & 3 & _ & 250.62 & 0.68 & 238.62 \\
\hline Synchrony $\sim 1+$ Calf age + Behavioural class $+(1 /$ Calf ID $)$ & 2 & 1 & 251.69 & 1.75 & 239.69 \\
\hline Synchrony $\sim 1+$ Calf age + Behavioural class $+(1 /$ Mother ID $)$ & 2 & 1 & 251.7 & 1.76 & 239.7 \\
\hline Synchrony $\sim 1+$ Calf age + Behavioural class + Sex $+(1 /$ Calf ID $)$ & 3 & 1 & 252.55 & 2.61 & 238.55 \\
\hline Synchrony $\sim 1+$ Calf age + Behavioural class + Sex $+(1 /$ Mother ID $)$ & 3 & 1 & 252.62 & 2.68 & 238.62 \\
\hline Synchrony $\sim 1+$ Calf age + Behavioural class + $(1 /$ Calf ID $)+(1 /$ Mother ID $)$ & 2 & 2 & 253.69 & 3.75 & 239.69 \\
\hline Synchrony $\sim 1+$ Calf age + Behavioural class + Sex $+(1 /$ Calf ID $)+(1 /$ Mother ID $)$ & 3 & 2 & 254.55 & 4.61 & 238.55 \\
\hline Synchrony $\sim 1+$ Behavioural class & 1 & _ & 254.96 & 5.02 & 246.96 \\
\hline Synchrony $\sim 1+$ Behavioural class + Sex & 2 & - & 255.45 & 5.51 & 245.45 \\
\hline Synchrony 1 + Behavioural class + (1 / Calf ID) & 1 & 1 & 256.24 & 6.3 & 246.24 \\
\hline Synchrony 1 + Behavioural class + (1 | Mother ID) & 1 & 1 & 256.32 & 6.38 & 246.32 \\
\hline Synchrony $\sim 1+$ Behavioural class + Sex $+(1 /$ Calf ID $)$ & 2 & 1 & 257.14 & 7.2 & 245.14 \\
\hline Synchrony $\sim 1+$ Behavioural class + Sex $+(1 /$ Mother ID $)$ & 2 & 1 & 257.45 & 7.51 & 245.45 \\
\hline Synchrony $\sim 1+$ Behavioural class $+(1 /$ Calf ID $)+(1 /$ Mother ID $)$ & 1 & 2 & 258.24 & 8.3 & 246.24 \\
\hline Synchrony $\sim 1+$ Behavioural class + Sex $+(1 /$ Calf ID $)+(1 /$ Mother ID $)$ & 2 & 2 & 259.14 & 9.2 & 245.14 \\
\hline Synchrony $\sim 1+$ Calf age + Sex $+(1 /$ Calf ID $)$ & 2 & 1 & 534.67 & 284.73 & 526.67 \\
\hline Synchrony $\sim 1+$ Calf age + Sex $+(1 /$ Mother ID $)$ & 2 & 1 & 534.67 & 284.73 & 526.67 \\
\hline Synchrony $\sim 1+$ Calf age $+(1 /$ Calf ID $)$ & 1 & 1 & 534.89 & 284.95 & 528.89 \\
\hline Synchrony $\sim 1+$ Calf age $+(1 /$ Mother ID $)$ & 1 & 1 & 535.07 & 285.13 & 529.07 \\
\hline Synchrony $\sim 1+$ Calf age + Sex $+(1 /$ Calf ID $)+(1 /$ Mother ID $)$ & 2 & 2 & 536.67 & 286.73 & 526.67 \\
\hline Synchrony $\sim 1+$ Calf age $+(1 /$ Calf ID $)+(1 /$ Mother ID $)$ & 1 & 2 & 536.89 & 286.95 & 528.89 \\
\hline Synchrony $\sim 1+$ Calf age + Sex & 2 & _ & 540.42 & 290.48 & 534.42 \\
\hline Synchrony $\sim 1+$ Calf age & 1 & _ & 544.7 & 294.76 & 540.7 \\
\hline Synchrony $\sim 1+$ Sex $+(1 /$ Calf ID $)$ & 1 & 1 & 586.78 & 336.84 & 580.78 \\
\hline Synchrony $\sim 1+$ Sex $+(1 /$ Calf ID $)+(1 /$ Mother ID $)$ & 1 & 2 & 588.78 & 338.84 & 580.78 \\
\hline Synchrony $\sim 1+\operatorname{Sex}+(1 /$ Mother ID $)$ & 1 & 1 & 590.53 & 340.59 & 584.53 \\
\hline Synchrony $\sim 1+$ Sex & 1 & _ & 690.6 & 440.66 & 686.6 \\
\hline
\end{tabular}



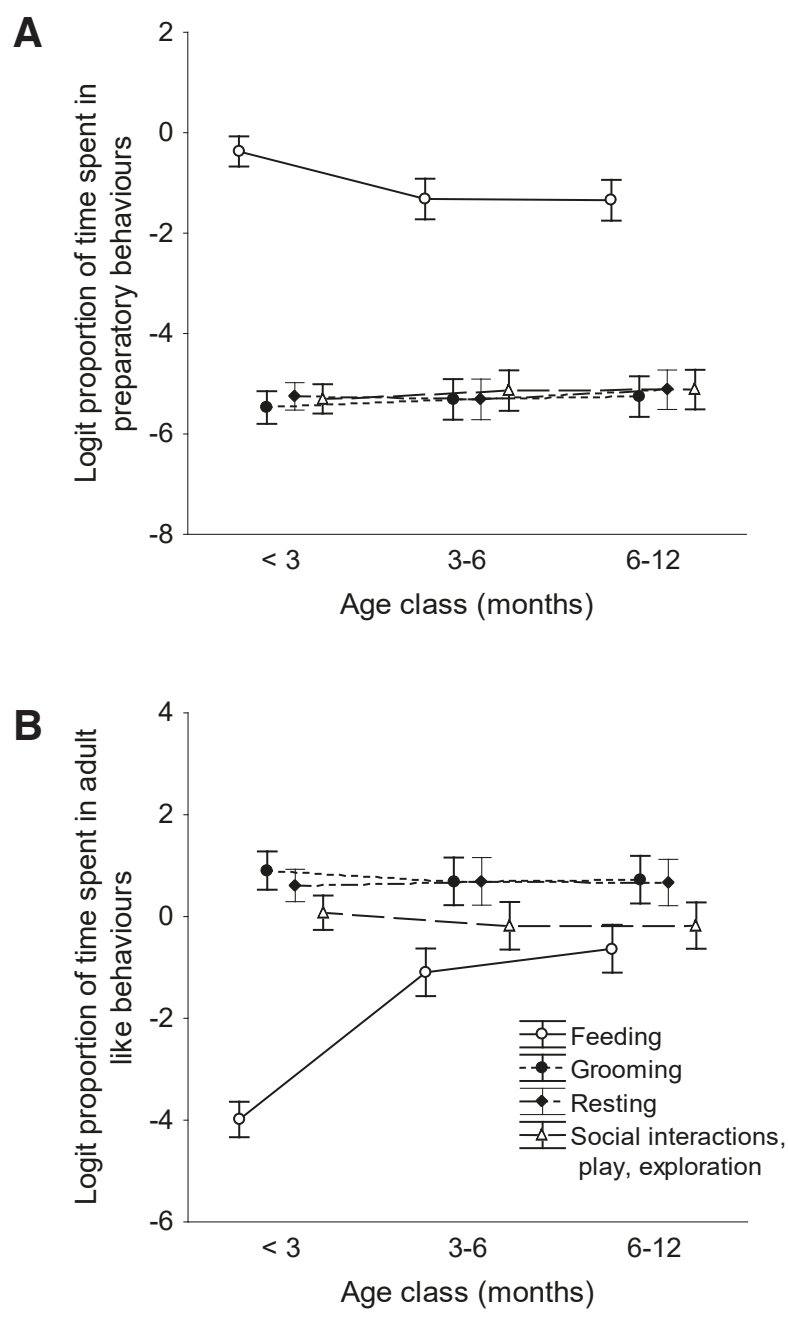

Fig. 11. Logit proportion of time spent in (A) preparatory behaviours and (B) adult-like behaviours, under different behavioural classes by calves belonging to three age classes.

and behavioural class (Table 4). However, there were also three other equally good models, whose $\triangle \mathrm{AIC}$ with the best model was smaller than 2. These models included calf sex, calf identity, and mother identity, respectively, in addition to calf age and behavioural class (Tables 4,5). Synchrony between mother and calf/juvenile based on resting-related behaviours increased dramatically between the age of less than six months (almost no synchrony) to about 2 years (almost complete synchrony) (Fig. 12). Synchrony in social interactions increased gradually throughout the period of being a calf and then juvenile. Synchrony in feeding was high throughout because elephants spend most of their waking hours in feeding-related activities. Grooming-related activities became less synchronised with increasing age of the offspring (Fig. 12).

\section{Discussion}

This is one of the first studies of the development of trunk motor control and behaviours in Asian elephant calves. We found that both trunk motor control and behaviours develop gradually over a period in this precocial species but trunk lateralisation occurs early on (the last also observed by Keerthipriya et al., 2015). As mentioned in the Introduction, Asian elephant calves can walk within hours of being born, albeit unsteadily, but do not use their trunk immediately (Nair 1989). We found that there was an effect of age on trunk motor use, with the proportions of unsuccessful clockwise and anticlockwise trunk movements and straight trunk touches decreasing from $<3$ months of age to about a year of age. However, there was no statistically significant independent effect of age on trunk lateralisation itself, as it seemed to arise very early in development, and only individual identity contributed to explaining lateralisation in successful trunk use. Many of the calves less than 3 months old already showed significant lateralisation and all the calves over 6 months of age showed significant lateralisation when the trunk was used successfully. Moreover, calves showed trunk side preferences even when they could not use the trunk successfully. A correlation between trunk motor skills (seen as lowered proportions of unsuccessful trunk movements or straight trunk touches) and lateralisation (based on successful trunk movements) would be seen if practice using the trunk gave rise to lateralisation due to its possibly increased efficiency. Although we found a negative correlation between the strength of successful trunk movements and the proportion of unsuccessful trunk movements and between the strength of successful trunk movements and the proportion of straight trunk touches, the values of the correlations were low. Therefore, it appears that lateralisation is not highly dependent on adeptness in trunk use. Since the inability to use the trunk successfully did not prevent lateralisation, it is possible that trunk lateralisation itself is innate, while trunk motor skills develop with age, and trunk lateralisation is probably not a good chronological marker of development in Asian elephants. Thus, precociality does not hasten the use of the trunk although limbs are used early on and trunk lateralisation occurs early. Since altricial mammals such

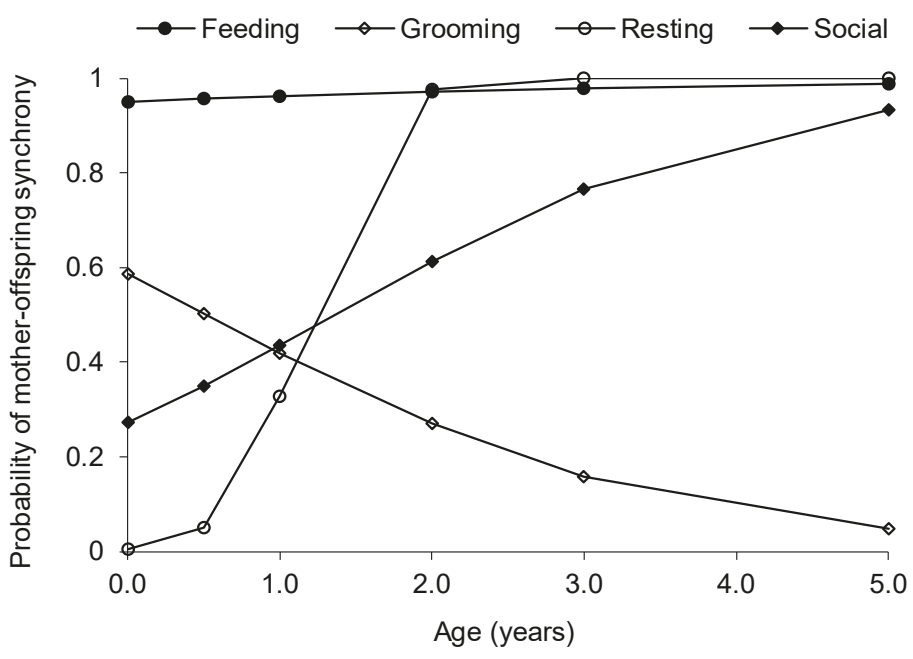

Fig. 12. Curves showing the expected probabilities of mother-offspring behavioural synchrony with calves/juveniles of different ages. The curves were obtained using logistic regression equations (without calf or mother identity as a random factor). The probability of synchrony under

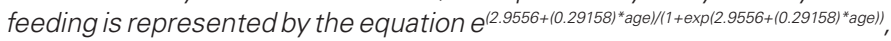
that under grooming is represented by the equation $e^{(0.34817+(-0.671809) * a g e)}$ $(1+\exp (0.34817+(-0.671809) * a g e)$, and the probability of synchrony under resting is represented by the equation $e^{(-5.1188+(4.40502) * a g e) /(1+\exp (-5.1188+(4.40502) * a g e)}$. The probability of synchrony under social interactions, play, and exploration is represented by the equation $\mathrm{e}^{\left(-0.98085+(0.720646)^{*} \text { age } /(1+\exp (-0.98085+(0.720646) * a g e))\right.}$. 
as chimpanzees, gorillas, and humans take several months to a few years to have set hand preferences (Ramsay 1980, Boesch 1991, Byrne and Byrne 1991), it had been suggested that trunk lateralisation may be correlated with precociality (Keerthipriya et al., 2015). Our results showing a lack of concordance between trunk motor ability and laterality now raise doubts about the hypothesis, although studies on other species will be required to test it.

Although precociality allows for early independent locomotion, we found that it took about one year - about the time it took for calves to approximate adult-like behavioural activity patterns - for trunk motor skills to be developed properly. This is consistent with the observations on a captive Asian elephant calf that showed increasingly fine motor skills from 2 to 17 weeks of age (Petraccione et al., 2017). Whereas both precocial and altricial species have the basic locomotor ability to perform alternating stepping limb movements soon after birth, the neuromuscular strength and coordination to support the body and actually walk soon after birth is present only in precocial species as these elements mature embryonically rather than postnatally as in altricial species (Muir 2000). It appears that similar neuromuscular strength and coordination required for trunk motor control develops only postnatally in elephants. This may result from phylogenetic inertia, in ontogeny, and it calls for an examination of the ontogeny of lateralisation in other related and unrelated species (such elephant shrews, which also belong to Afrotheria, and tapirs) that have elongated noses. Unlike the precociality in limb use, it is possible that in the ancestral state, when a modification of the upper lip evolved, the development of strength and coordination of the structure may have taken place postnatally rather than during the embryonic stages. Therefore, when the trunk evolved in elephants, its functional development, as a result of being constrained by its phylogeny, may have continued to occur postnatally. In fact, the upper lip and proboscis are not fused together during the early foetal ontogeny in the African savannah elephant (Fischer and Trautmann 1987). Phylogenetic inertia in ontogeny of lateralisation of the trunk may be examined by studying the development

TABLE 5

PARAMETER ESTIMATES AND THEIR CONFIDENCE INTERVALS AND STATISTICAL SIGNIFICANCE FROM THE BEST MODELS TO EXPLAIN MOTHER-OFFSPRING SYNCHRONY

\begin{tabular}{|c|c|c|c|c|c|c|c|}
\hline \multirow{2}{*}{$\begin{array}{l}\text { Effect } \\
\text { Model: Synchrony } \sim 1+\text { Calf age }+ \text { Behavioural class }\end{array}$} & \multirow[t]{2}{*}{ Estimate } & \multirow[t]{2}{*}{ SE } & \multirow[t]{2}{*}{$t$} & \multirow[t]{2}{*}{$d f$} & \multirow[t]{2}{*}{$P$ value } & \multicolumn{2}{|c|}{$95 \% \mathrm{Cl}$} \\
\hline & & & & & & & \\
\hline \multicolumn{8}{|l|}{ Fixed effects } \\
\hline Intercept & -0.628 & 0.277 & -2.268 & 510 & 0.024 & -1.172 & -0.084 \\
\hline Calf age & 0.450 & 0.179 & 2.517 & 510 & 0.012 & 0.099 & 0.800 \\
\hline Behavioural class - Resting & -2.880 & 0.408 & -7.057 & 510 & $<0.001$ & -3.681 & -2.078 \\
\hline Behavioural class - Social interaction, play, exploration & -0.139 & 0.281 & -0.494 & 510 & 0.622 & -0.690 & 0.456 \\
\hline Behavioural class - Feeding & 3.403 & 0.333 & 10.211 & 510 & $<0.001$ & 2.748 & 0.456 \\
\hline \multicolumn{8}{|l|}{ Random effects } \\
\hline Error & 1.000 & & & & & & \\
\hline \multicolumn{8}{|l|}{ Model: Synchrony $\sim 1+$ Calf age + Behavioural class + Sex } \\
\hline \multicolumn{8}{|l|}{ Fixed effects } \\
\hline Intercept & -0.663 & 0.279 & -2.374 & 509 & 0.018 & -1.211 & -0.114 \\
\hline Calf age & 0.439 & 0.176 & 2.493 & 509 & 0.013 & 0.093 & 0.785 \\
\hline Behavioural class - Resting & -2.851 & 0.408 & -6.982 & 509 & $<0.001$ & -3.653 & -2.049 \\
\hline Behavioural class - Social interaction, play, exploration & -0.133 & 0.281 & -0.473 & 509 & 0.637 & -0.685 & 0.420 \\
\hline Behavioural class - Feeding & 3.407 & 0.334 & 10.208 & 509 & $<0.001$ & 2.751 & 4.062 \\
\hline Sex & -0.200 & 0.175 & -1.148 & 509 & 0.252 & -0.544 & 0.142 \\
\hline \multicolumn{8}{|l|}{ Random effects } \\
\hline Error & 1.000 & & & & & & \\
\hline \multicolumn{8}{|c|}{ Model: Synchrony $\sim 1+$ Calf age + Behavioural class $+(1 /$ Calf ID $)$} \\
\hline \multicolumn{8}{|l|}{ Fixed effects } \\
\hline Intercept & -0.657 & 0.300 & -2.187 & 510 & 0.029 & -1.247 & -0.669 \\
\hline Calf age & 0.468 & 0.189 & 2.472 & 510 & 0.014 & 0.096 & 0.840 \\
\hline Behavioural class - Resting & -2.931 & 0.420 & -6.986 & 510 & $<0.001$ & -3.755 & -2.107 \\
\hline Behavioural class - Social interaction, play, exploration & -0.175 & 0.286 & -0.611 & 510 & 0.54 & -0.737 & 0.387 \\
\hline Behavioural class - Feeding & 3.496 & 0.344 & 10.156 & 510 & $<0.001$ & 2.820 & 4.173 \\
\hline \multicolumn{8}{|l|}{ Random effects } \\
\hline Calf ID intercept & 0.410 & & & 45 levels & & & \\
\hline Error & 1.000 & & & & & & \\
\hline \multicolumn{8}{|c|}{ Model: Synchrony $\sim 1+$ Calf age + Behavioural class $+(1 /$ Mother ID $)$} \\
\hline \multicolumn{8}{|l|}{ Fixed effects } \\
\hline Intercept & -0.658 & 0.300 & -2.192 & 510 & 0.029 & -1.247 & -0.680 \\
\hline Calf age & 0.469 & 0.189 & 2.480 & 510 & 0.013 & 0.097 & 0.840 \\
\hline Behavioural class - Resting & -2.930 & 0.420 & -6.986 & 510 & $<0.001$ & -3.754 & -2.106 \\
\hline Behavioural class - Social interaction, play, exploration & -0.174 & 0.286 & -0.609 & 510 & 0.543 & -0.736 & 0.388 \\
\hline Behavioural class - Feeding & 3.496 & 0.344 & 10.161 & 510 & $<0.001$ & 2.820 & 4.172 \\
\hline \multicolumn{8}{|l|}{ Random effects } \\
\hline Mother ID intercept & 0.408 & & & 45 levels & & & \\
\hline Error & 1.000 & & & & & & \\
\hline
\end{tabular}


and laterality of the upper lip and nose of related species. Elephants do not have many close relatives, but elephant shrews, aardvarks, and hyraxes that also belong to the clade Afrotheria could possibly be studied. One could also study the ontogeny and lateralisation of the elongated noses of tapirs, which are not related to elephants, and relatives of tapirs such as horses, donkeys, and zebras (the tapirs also do not have close relatives).

Our results on the behaviours displayed by calves showed that various behaviours developed over a period of time, resulting in an approximation of adult-like behaviour at the age of about 1-2 years, although there were more subtle changes in activity budgets until the age of about 5-10 years. Behaviours that require trunk control, such as some feeding-related behaviours, developed gradually as trunk motor control also developed over several months, while adult-like behaviours were seen in the context of grooming and resting. In wild African savannah elephants and captive Asian elephants, some of the first behavioural elements to develop were those related to locomotion, resting, and sucking (Lee 1986, Nair 1989, Moss et al., 2011) - these are behaviours that do not require trunk usage.

We found that young calves spent considerable time in practicing the preparatory steps to feeding. They spent time sniffing the grass, trying to hold and pluck it, investigating the grass collected by conspecifics, and, sometimes, sitting on the ground to nibble grass blades directly without using the trunk. Adult-like feeding behaviours were primarily shown by calves that were older than 3 months of age, and older calves (6-12 months) spent the highest proportion of time in expressing adult-like feeding patterns. Nair (1989) had examined the sequence of events involved in feeding and found that only the older calves (> 6 months) approximated an adult-like feeding sequence (hold-pull-place in mouth). However, although the proportion of adult-like behaviours and the time spent in feeding increased as the calves became older, the duration of feeding activities did not differ between the younger and older calves, suggesting that efficiency in feeding was not fully developed by 1 year of age and might take longer to reach an adult's level of competence. In captive Asian elephants, it was observed that the diversity of food species available to calves was much less than that available to juveniles and subadults, and some of the food species require substantial physical force to procure, which a calf is not capable of (Nair 1989). Thus, the skills required to perfect feeding behaviour might be practiced and elaborated beyond this period.

Most of the resting-related behaviours exhibited by calves resembled those of adults, although most of the calf resting bouts involved them lying down on the ground while subadults and adults usually rested standing up. During the initial few weeks after birth, calves were seen leaning on the mother to rest and were sliding down against her leg to rest on the ground. Most of the grooming and social interactions, play and exploration related behaviours shown by calves were also adult-like, except for certain grooming behaviours, such as spraying dust onto oneself, that requires control over the trunk. In African savannah elephants, it was found that the social interaction rate and the kinds of responses to these interactions differed between calves and juveniles and between the sexes (Lee 1986, Moss et al., 2011, Webber 2017). We did not examine the behaviours of juveniles of different sexes, but we did not find an effect of sex on trunk lateralisation and motor development in calves. We also examined the effect of sex on calf behaviour in our preliminary analyses but did not find an effect and pooled the data together to improve sample sizes. In Asian elephants, Webber (2017) also did not find an effect of sex on the time calves spent feeding, moving, or resting. We, however, found sex to be a factor in one of the best models explaining synchrony between mother and calf.

The proportion of time spent on resting-related behaviours decreased with age, with young calves showing the highest proportion of time spent resting, similar to that found in captive Asian elephant populations (Gadgil and Nair 1984, Nair 1989 , Webber 2017) and in African savannah elephants (Lee 1986, Moss et al., 2011, Webber 2017). Since elephants are megaherbivores and spend $\sim 50 \%-75 \%$ of their time feeding (McKay 1973, Sukumar 2003, Baskaran et al., 2010), resting by calves would be a cost to the mother, restricting movement required to find forage. The mother may sometimes be extremely restricted if she stands over a young calf to provide shade (as elephants can get dangerously over-heated). The activity budget hypothesis (Ruckstuhl 1998, Ruckstuhl and Neuhaus 2001), proposed initially in the context of sexual segregation, suggested that the degree of within group synchrony may be influenced by the differences in physiological demands between individuals arising from variations in reproductive stage, sex, or age. Since synchronisation of activities of a heterogeneous group would entail costs through individuals making compromises, such groups may segregate or fission along common lines.

The nutritional requirements of an elephant calf are different from that of the mother, and there are substantial differences in the activity budgets of the calf and mother. In the case of bottlenose dolphins, which also have precocial motor skills and a long period (3-8 years) of nursing, calves, even newborns, can temporarily separate from their mothers and swim alone or with other conspecifics (Mann and Smuts 1999, see Gibson and Mann 2008). In harp seals, which are also precocial, females leave their pups after 2 days of birth and swim out to feed, returning to nurse the pups once in a while, spending only about $15 \%$ of their time with the pups (Kovacs 1987). The young ones of giraffes are "hiders", remaining separated from the mother after birth except during nursing (Langman 1977). Since none of these is the case in the Asian elephant, the calf being dependent on the mother, behaviours that decrease synchrony may decrease rapidly with calf age if synchrony is expensive. We found that the proportion of time spent resting was significantly lower in calves older than 6 months of age than in calves below 3 months of age, and juveniles over 1 year of age were similar to adult females in their proportion of time spent resting. The proportion of time spent feeding increased with calf age but was not accompanied by a significant increase in the mother-offspring feeding synchrony because adult females spend most of their time feeding. Synchrony in social interactions between the mother-offspring pair increased with age although the proportion of time spent in these behaviours or the durations of these behaviours did not increase with age. It is not clear if calves or their mothers influence one another such that these behaviours coincide more frequently.

The pattern of a continuous increase or decrease in behaviours across age classes as we found in Asian elephant calves is not the only kind of behavioural ontogeny expected. The ontogeny of behaviour in young ones may be a smooth, gradual transition from imperfect or underdeveloped behavioural state to a range 
of completely developed adult behaviours (Klopfer 1988) or could vary in other ways. Bottlenose dolphin calves, which can socialise partly independently of their mother, have a peak in socialising during the first year, followed by a decline (Gibson and Mann 2008). The ontogeny of behaviour is marked by abrupt discontinuities as a result of the differences in the ecology and social environment between the young and the adult in the spotted hyena (Holekamp and Smale 1998). Spotted hyena neonates are precocial, with eyes open and a moderately advanced dentition (Kruuk 1972). They socialize exclusively with their mother and sibling (establishing a dominance relationship with the sibling) in the natal den in the first few weeks after birth, followed by socialising with others when transferred to the communal den (Frank et al., 1991, Holekamp and Smale 1998). Therefore, play and fighting behaviours may show abrupt changes although feeding behaviours develop gradually (Holekamp and Smale 1998). Orangutans showed more continuous change, with feeding, and social play behaviours increasing with age, but resting and nonsocial play decreasing with age (Mendonca et al., 2016).

Although we found trunk motor skills and behaviours to develop gradually over several months, they developed over a very short time relative to the lifespan (over 70 years, see Sukumar 2003) of the species, although individuals can continue to learn social behaviours as they grow into juveniles, subadults, and adults. They developed over a relatively short time compared to the time to weaning also, as elephants are seen to nurse for at least two years and the weaning is gradual (personal observations). Harp seal pups are highly precocious and weaned abruptly when they are just 12-15 days old, but remain predominantly immobile before that, mostly only shifting positions, and abruptly taking to the water to swim without any 'teaching' (Kovacs 1987). Orangutans have a prolonged period of dependence on the mother, being in continuous body contact for the first three months, being assisted with locomotion until they are about 3 years of age, and being suckled up to 7 years of age, due to their solitary lifestyle that necessitates that the young are ecologically competent before they are weaned (van Noordwijk and van Schaik 2005). In social species like the Asian elephant, weaned juveniles can continue to receive information or protection from others in their clan. It would be interesting to examine the effect of interaction of precociality/ altriciality and sociality on the ontogeny of behaviour.

Thus, we found that while elephant calves may be anatomically and physiologically well developed at birth, fine motor skills and some of the social and non-social behaviours develop over many months. With increase in control over motor skills, calves begin to show complex behaviours that require dexterity in trunk usage, and their behavioural repertoire begins to match that of an adult. The efficiency with which calves performed various behaviours like feeding also improved with age. We found that laterality in trunk usage and certain behaviours such as sucking, resting, and less complex grooming behaviours seemed to be innate as calves showed these from a very young age. As trunk motor control and trunk-limb coordination necessary to pluck and process grass take several months to develop, the prolonged period of offspring dependency on the mother can be highly crucial and beneficial in terms of nutritional support. This period might also be beneficial in view of defense against predators and development of important social skills, and can be examined in the future.

\section{Materials and Methods}

\section{Field data collection}

The data used in this study were collected from December 2015 to December 2017. Field work was conducted in Nagarahole National Park and Tiger Reserve $\left(11.85304^{\circ}-12.26089^{\circ} \mathrm{N}, 76.00075^{\circ}-76.27996^{\circ} \mathrm{E}\right)$ and Bandipur National Park and Tiger Reserve (11.59234 ${ }^{\circ}-11.94884^{\circ}$ $\mathrm{N}, 76.20850^{\circ}-76.86904^{\circ} \mathrm{E}$ ) in southern India. Nagarahole and Bandipur National Parks primarily comprise dry and moist deciduous forests and are separated by the Kabini reservoir. During the dry season (mid-December to mid-June), as water recedes, abundant fresh grass becomes available and it results in a large congregation of herbivores around the backwaters (Vidya et al., 2014). Most of the behavioural data was collected from around the backwaters because of good visibility. The Kabini Elephant Project has recorded hundreds of individually identified elephants and this population (called the Kabini elephant population henceforth) has been studied since 2009 (Vidya et al., 2014). Field work was typically carried out from $\sim 6 \mathrm{AM}$ to 7 PM during the dry season and from $\sim 6$ AM to $\sim 6$ PM during the wet season. Elephant groups were observed from a distance of over $40 \mathrm{~m}$ to avoid any disturbance to their natural activity. When elephants were sighted, they were age-sex classified and individually identified. Animals were aged based on shoulder height, body length and bulk. They were categorised into broad age categories as calf $(<1$ year), juvenile $(1-<5$ years), subadult $(5-<10$ years in the case of females and $5-<15$ years in the case of males), or adult ( $>=10$ or 15 years, for females and males, respectively). Birth records for identified females were maintained from 2009 and the date and place of birth (if known) and the sex of calves were recorded. Thus, by 2015, more accurate ages were known for calves and juveniles (based on when the mother was sighted last without a calf and when she first appeared with the calf), as they were born after the beginning of the Kabini Elephant Project, while adults were placed into 10-year age classes. Asian elephants are sexually dimorphic and were sexed based on genitalia. Photos, videos, and/or sketches of the elephant's ears, tail, tail hair, back shape, wounds and warts (if any), and tusks (in the case of males) or tushes were used to identify individuals (see Vidya et al., 2014).

Female elephants in the population are socially organised into clans, which are the most inclusive level of social structure (Nandini et al., 2018). However, entire clans are rarely seen together. Instead, subsets of females from the clan form small groups, which may change in composition through fission-fusion dynamics (Nandini et al., 2017). We identified a female group as a set of females showing coordinated movement and behaviour, and usually within 50-100 $\mathrm{m}$ of one another. The location of the group was recorded using a GPS and behavioural observations were carried out when the group was undisturbed and in clear sight. We carried out scan sampling (Altmann 1974) at half-hour intervals and wrote down the behaviour shown by each individual in the group during each "instantaneous" scan. In the intervals between the scans, we carried out focal animal sampling (Altmann 1974) for 20 minutes, during which we recorded the activities of individually identified calves or juveniles in the group using a SONY handycam (HDR-PJ540E).

\section{Behaviour scoring and data analyses}

We used the focal videos recorded in the field to score for trunk use and various behaviours.

\section{Trunk use and side preference}

We scored for trunk use of individually identified calves and juveniles during 5 minutes ( \pm 3 seconds) of focal videos on a given day. While it was theoretically possible to use the entire focal video to score for various behaviours, only parts of the video when the trunk tip was clearly visible could be used for scoring trunk use (as the orientation of the trunk tip was sometimes not visible even in the short grass). During this period, we noted 1 ) the numbers of times the focal individual used the trunk in clockwise 
and anticlockwise directions to pluck, gather, or grab vegetation or other objects successfully, 2) the numbers of times the focal individual attempted to move the trunk in clockwise and anticlockwise direction but did not successfully pluck vegetation or other objects, and 3) the number of times the focal individual touched the ground straight, without curling the tip of the trunk (see Fig. 1). Additionally, 4) the number of times vegetation or other objects were placed on the right or left side of the mouth (Fig. 1) and 5) and the number of times the individual touched the right or left side of its body were noted. Whenever the trunk movement, placement of grass or other objects and body touch was not clearly visible it was considered to be an unresolved movement/placement/body touch and not considered for analysis.

The direction of side preference was measured using the lateral bias index (Bard etal., 1990), calculated as $(R-L) /(R+L)$, where $R$ was the number of trunk movements towards the right (or clockwise) and $L$ was the number of trunk movement towards the left (or anti-clockwise). Positive values of the index, therefore, indicated a right side bias and negative values, a left side bias. Binomial tests were used to check for statistically significant side bias (clockwise/anticlockwise) in trunk movement while plucking and gathering vegetation or other objects successfully and unsuccessfully, for preference in the placement of vegetation or other objects on the right or left side of the mouth, and for preference in the side of the body touched. The absolute value of the lateral bias index indicates the strength of lateralisation, with 0 indicating no side bias and 1 indicating strong side bias.

Since our dataset included repeated observations on the same individuals within and across age classes, we carried out repeated measures ANOVAs on the variable examined for lateralisation (such as logit proportion of clockwise successful or unsuccessful trunk movement, logit proportion of right side trunk placement in the mouth, etc.) by the same individuals, across days but within the same age class. We used four age classes for this purpose: $<3$ months old, 3-6 months, $6-12$ months, and $>12$ months. We also used sex and age class as categorical factors in the ANOVA. If there was little variability across days sampled within the same age class, one sample from each individual during that age class could be used to construct the distributions of lateral bias index or strength, without biasing this due to multiple sampling of some individuals. We found consistency in direction overall within individuals sampled on different days within an age class even at young ages and, therefore, created subsets of the different datasets (successful trunk movement, unsuccessful trunk movement, straight trunk touch, trunk placement in the mouth, and body touch) with each individual being represented only once in a particular age class. If an individual was sampled more than once in the same age class, only the first sampling instance was included.

We used mixed-effects models to statistically examine the effect of age class on the strengths of different types of trunk lateralisation (successful and unsuccessful trunk use, mouth placement, and body touch) and proportions of unsuccessful trunk use (calculated by dividing the number of clockwise and anticlockwise unsuccessful trunk movements by the total number of clockwise and anticlockwise successful and unsuccessful trunk movements) and straight trunk touches (calculated by dividing the number of straight touches by the total number of trunk movements, including straight touches and clockwise and anticlockwise successful and unsuccessful trunk movements). In these models, which were run using Statistica 7 (StatSoft, Inc. 2004), age class ( $<3$ months, 3-6 months, 6-12 months and greater than 12 months) was the fixed factor and individual identity of the calf/juvenile was a random factor. We logit transformed the dependent variables because they were highly non-normal, but the results remained similar when the analyses were performed on the untransformed data also. We expected trunk side preferences to increase with age in the context of feeding but not in the context of body touches.

\section{Behaviour data: activity budget, behaviour duration, and age}

While the various behaviours seen during the scans (at 30-minute intervals) had been written down in the field, video footage of focal animal sampling was scored for various behaviours (see Supplementary Figs. S1-4 and Supplementary Table 1). Focal animal scoring was carried out on a second-by-second basis to obtain fine-scale details about the behaviours displayed. Various behaviours were identified and described based on these focal videos (see Supplementary Figs. S1-4 and Supplementary Table 1). These behaviours were classified based on their nature as feeding, resting, grooming, or social (including exploratory behaviours and play) behavioural classes.

The behaviours of all identified individuals noted during scan sampling were used to construct activity budgets for different age classes of individuals. Since scan sampling sampled all individuals in the group, we could compare calves with adults using this data. We then used the focal animal sampling data on calves to examine the proportion of the focal duration that calves of different age-classes spent displaying behaviours belonging to the different behavioural classes. This was done by running a General Linear Model (GLM) on the logit proportion of time spent in various behaviours, with age-class and behavioural class of calf action as fixed factors and calf identity as a random factor. The three age classes used were $<3$ months, 3-6 months, and 6-12 months. We further wanted to check if there was any difference in the proportion of time spent in different behavioural classes within the first three months after birth. Hence, we also divided calves into four age classes: $<1$ month, 1-2 months, $2-3$ months, and $>3$ months and repeated the GLM. Since focal animal sampling of calves was carried out on a second-by-second basis, we also examined the duration of various behaviours shown and used a GLM to find out whether age-class and behavioural class (fixed factors) or calf identity (random factor) affected behaviour duration.

\section{Behaviour data: behavioural stages and age}

We also classified behaviours based on the skill of execution and broad timing of behaviour as calf-specific, adult-like, preparatory adult behaviour (if it was an incipient stage of an adult-like behaviour but not executed with much skill), or preparatory calf behaviour (if it was an incipient stage of a calf-specific behaviour but not executed with much skill) (see Supplementary Figs. S1-4 and Supplementary Table 1). We wanted to examine when adult-like behavioural expression develops. We, therefore, calculated the proportions of time spent by calves in showing preparatory, calf-specific, preparatory calf, and adult-like behaviours under the four behavioural classes mentioned above and ran GLMs using age class and behavioural class as fixed factors and calf identity as a random factor. We used the age classes $<3$ months, 3-6 months, and $6-12$ months, but also additionally used $<1$ month, 1-2 months, 2-3 months, and $>3$ months for this analysis.

\section{Behavioural synchrony between mother and calf}

We calculated the behavioural-class synchrony between calves/juveniles and their mothers, with synchrony being 1 if the calf/juvenile and its mother showed behaviours belonging to the same behavioural class during a particular scan, and synchrony being 0 if they showed behaviours belonging to different behavioural classes during that scan. We ran generalized linear mixed-effects models with synchrony as a binomial dependent variable, age of the calf/juvenile and behavioural class as fixed factors, and identities of the calf/juvenile and mother as random factors. The analysis was carried out using the fitglme function in MATLAB R2011a, with a logit link function. $\triangle \mathrm{AIC}$ values were calculated as the difference between the AIC of the best model (i.e. the model with the smallest AIC value) and the AIC of each of the other models, in order to find out whether there were multiple 'best' models (if the $\triangle \mathrm{AIC}$ values were less than 2).

\section{Acknowledgements}

This work was funded by the Council of Scientific and Industrial Research, Government of India, under Grant No. 37(1613)/13/EMR-II and Jawaharlal Nehru Centre for Advanced Scientific Research (JNCASR). TR and SA were supported as students by JNCASR. This work is part of TR's Ph.D. thesis. We thank the offices of the PCCF, Karnataka Forest Department, and of the Conservators of Forests of Nagarahole and Bandipur National Parks and Tiger Reserves for field permits. We also thank various officials, 
from the PCCF and APCCF, to the Conservators of Forests and Range Forest Officers, to the staff of Nagarahole and Bandipur National Parks for their support. We thank Krishna, Shankar, Pramod and others for help in the field, and Hansraj Gautam for some videos.

\section{References}

ALTMANN J (1974). Observational study of behaviour: sampling methods. Behaviour 49: 3-4.

BARD KA, HOPKINS W D, and FORT C L (1990). Lateral bias in infant chimpanzees (Pan troglodytes). J Comp Psychol 104: 309-321.

BARRETT P and BATESON P (1978). The development of play in cats. Behaviour 66:106-120.

BASKARAN N, BALASUBRAMANIAN M, SWAMINATHAN S and DESAI AA (2010). Feeding ecology of the Asian elephant Elephas maximus Linnaeus in the Nilgiri Biosphere Reserve, southern India. J Bombay Nat Hist Soc 107: 3-13.

BATESEON P (1981). Ontogeny of behaviour. Br Med Bull 37: 159-164.

BATESON P (1987). Biological approaches to the study of behavioural development. Int J Behav Dev 10: 1-22.

BATESON P (2017). Behaviour, Development and Evolution. Cambridge, UK: Open book publishers.

BOESCH C (1991). Teaching among wild chimpanzees. Anim Behav 41: 530-532.

BYRNE R W, BYRNE J M E (1991). Hand preferences in the skilled gathering tasks of mountain gorillas (Gorilla g. beringei). Cortex 27: 521-546.

CONRADT $L$ (1998) Could asynchrony in activity between the sexes cause intersexual social segregation in ruminants? Proc R Soc Lond [Biol] 265: 1359-1363.

DERRICKSON E M (1988). The effect of experimental termination of lactation on subsequent growth in Peromyscus leucopus. Can J Zool 66: 2507-2512.

DERRICKSON E M (1992). Comparative reproductive strategies of altricial and precocial eutherian mammals. Funct Ecol 6: 57-65.

FISCHER M S and TRAUTMANN U (1987). Fetuses of African elephants (Loxodonta africana) in photographs. Elephant 2: 40-45.

FRANK G L, GLICKMAN F L, and LICHTP (1991). Fatal Sibling Aggression, Precocial Development, and Androgens in Neonatal Spotted Hyenas. Science 252: 702-704.

GADGIL M and NAIR P V (1984). Observations on the social behaviour of free ranging groups of tame Asiatic elephant (Elephas maximus Linn). Proc Indian Acad Sci (Anim Sci) 93: 225-233.

GIBSON Q A and MANN J (2008). Early social development in wild bottlenose dolphins: sex differences, individual variation and maternal influence. Anim Behav 76: 375-387.

GILJOV A, KARENINAK, and MALASHICHEVY (2018). Facing each other: mammal mothers and infants prefer the position favouring right hemisphere processing. Biol Lett 14: 20170707.

HINDE RA and BATESON P (1984). Discontinuities versus continuities in behavioural development and the neglect of process. Int J Behav Dev 7: 129-143.

HOLEKAMP K E and SMALE L (1998). Behavioural development in the spotted hyena. Biosci 12: 997-1005.

JOFFE T H (1997). Social pressures have selected for an extended juvenile period in primates. J Hum Evol 32: 593-605.

KEERTHIPRIYA P, TEWARI R, and Vidya T N C (2015). Lateralization in trunk and forefoot movements in a population of free-ranging Asian elephants (Elephas maximus). J Comp Psychol 129: 377.

KLEIMAN D G (1972). Maternal behaviour of the green acouchi (Myoprocta pratti Pocock), a South American caviomorph rodent. Behaviour 43: 48-84.

KLOPFER P (1988). Metaphors for development: How important are experiences early in life? Dev Psychobiol 21: 671-678.

KOVACS K M (1987). Maternal behaviour and early behavioural ontogeny of harp seals, Phoca groenlandica. Anim Behav 35: 844-855.

KRUUK H (1972). The Spotted Hyena. Chicago: University of Chicago Press.

LANGMAN V A (1977). Cow-calf relationships in giraffe (Giraffa camelopardalis giraffa). Z Psychol 43: 264-286.

LEE P C (1986). Early social development among African elephant calves. Natl Geogr Res 2: 388-401.
LEE P C and MOSS C J (1986). Early maternal investment in male and female Asiatic elephant calves. Behav Ecol and Sociobiol 18: 353-361.

MANN J and SMUTS B B (1999) Behavioural development in wild bottlenose dolphin newborns (Tursiops sp.). Behaviour 136: 529-566.

MAR K U, LAHDENPERÄ M, and LUMMAA V (2012). Causes and correlates of calf mortality in captive Asian elephants (Elephas maximus). PLoS One 7: e32335

MCKAY G M (1973). Behaviour and ecology of the Asiatic elephant in southeastern Ceylon. Smithson Contrib Zool 125: 1-113.

MARTIN F, and NIEMITZ C (2003). "Right-trunkers" and "left-trunkers": side preferences of trunk movements in wild Asian elephants (Elephas maximus). J Comp Psychol 117: 371.

MENDONCA R S, KANAMORI T, KUZE N, HAYASHI M, BERNARD H, and MATSUZAWA T (2016). Development and behavior of wild infant-juvenile East Bornean orangutans (Pongo pygmaeus morio) in Danum Valley. Primates, 58: 211-224.

MOSS C J, CROZE H, AND LEE P C (Eds.) (2011). The Amboseli Elephants: A Long-term Perspective on a Long-lived Mammal. University of Chicago Press, Chicago, Illinois.

MUIR G D (2000) Early ontogeny of locomotor behaviour: a comparison between altricial and precocial animals. Brain Res Bull 53: 719-726.

NAIR P V (1989). Development of nonsocial behaviour in the Asiatic elephant. Ethology 82: 46-60.

NANDINI S, KEERTHIPRIYA P and VIDYA T N C (2017). Seasonal variation in female Asian elephant social structure in Nagarahole-Bandipur, southern India. Anim Behav 134: 135-145.

NANDINI S, KEERTHIPRIYAP and VIDYA T N C (2018). Group size differences may mask underlying similarities in social structure: a comparison of female elephant societies. Behav. Ecol. 1-15.

PETRACCIONE J, ROOT-GUTTERIDGE H, CUSANO D A, and PARKS D E (2017). Exploring the early social affiliations and behaviour of a captive Asian elephant (Elephas maximus) calf. $J$ Zoo Aquar Res 5: 131-136.

POIRIER F E and SMITH E O (1974). Socializing functions of primate play. Am Zool 14: 275-287.

PRATT D M and ANDERSON V H (1979). Cow-calf relationships and the social development of the calf in the Serengeti. Z Psychol 51: 233-251.

RAMSAY D (1980). Onset of unimanual handedness in infants. Infant Behav Dev 3: $377-385$.

ROGERS LJ (2002). Lateralised brain function in anurans: Comparison to lateralisation in other vertebrates. Laterality 7: 219-239.

RUCKSTUHL K E (1998). Foraging behaviour and sexual segregation in bighorn sheep. Anim Behav 56: 99-106.

RUCKSTUHL K E and NEUHAUS P (2001). Behavioural synchrony in ibex groups: effects of age, sex and habitat. Behaviour 138: 1033-1046.

SCHEIBER I B R, WEI $\beta$ B M, KINGMA S A and KOMDEUR J (2017). The importance of the altricial - precocial spectrum for social complexity in mammals and birds - a review. Front Zool 14:3.

SCOTT J P, STEWART J M, and De GHETT V J (1974). Critical periods in the organization of systems. Dev Psychobiol 7: 489-513.

SHARMA R and KRISHNAMURTHY K V (19840. Behavior of a neonate elephant (Elephas maximus). Appl Anim Behav Sci 13: 157-161.

SUKUMAR R (2003). The Living Elephants: Evolutionary Ecology, Behavior, and Conservation. Oxford University Press, New York.

Van NOORDWIJK M A and Van SCHAIK C P (2005). Development of ecological competence in Sumatran orangutans. Am J Phys Anthropol 127: 79-94.

VIDYA T N C, PRASAD D and GHOSH A (2014). Individual identification in Asian elephants. Gajah 40: 3-17.

WASHBURN S and HAMBURG D (1965). The implications of primate research. In Primate behavior: field studies of monkeys and apes (Ed. Irven DeVore). New York: Holt, Rinehart, and Winston, pp. 607-623.

WEBBER C E (2017). A Comparison of Behavioural Development of Elephant Calves in Captivity and in the Wild: Implications for Welfare (PhD Dissertation). University of Sterling. http://hdl.handle.net/1893/27503 


\section{Further Related Reading, published previously in the Int. J. Dev. Biol.}

Avian models and the study of invariant asymmetry: how the chicken and the egg taught us to tell right from left Anne H. Monsoro-Burq and Michael Levin

Int. J. Dev. Biol. (2018) 62: 63-77

https://doi.org/10.1387/ijdb.180047ml

Left-right asymmetry specification in amphioxus: review and prospects

Vladimir Soukup

Int. J. Dev. Biol. (2017) 61: 611-620

https://doi.org/10.1387/ijdb.170251vs

Development vs. behavior: a role for neural adaptation in evolution?

Alain Ghysen and Christine Dambly-Chaudière

Int. J. Dev. Biol. (2016) 60: 77-84

Generation of pattern and form in the developing limb

Matthew Towers and Cheryll Tickle

Int. J. Dev. Biol. (2009) 53: 805-812

Brain switching: studying evolutionary behavioral changes in the context of individual brain development

Evan Balaban

Int. J. Dev. Biol. (2005) 49: 117-124
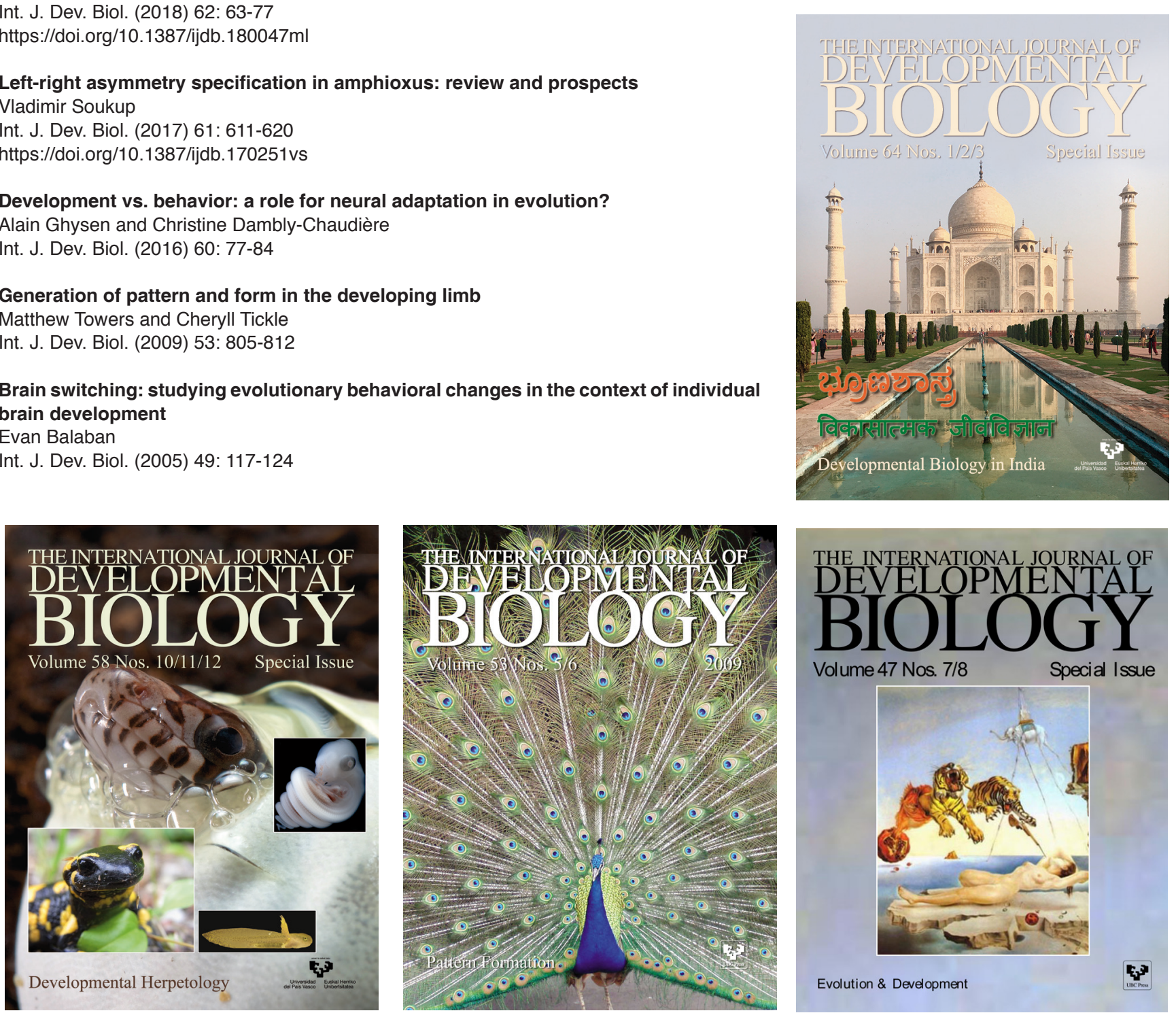

Special Issue

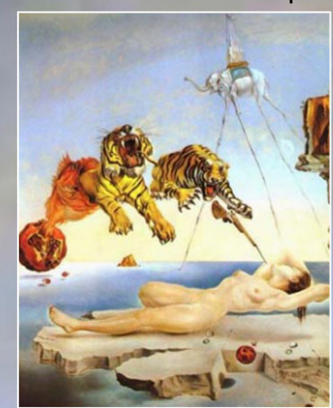

Evolution \& Development 